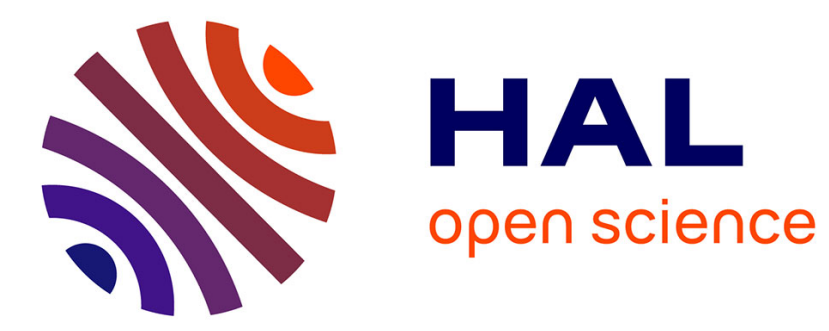

\title{
Identifying global seismic anisotropy patterns by correlating shear-wave splitting and surface-wave data
}

Andreas Wuestefeld, Goetz Bokelmann, Guilhem Barruol, Jean-Paul

Montagner

\section{- To cite this version:}

Andreas Wuestefeld, Goetz Bokelmann, Guilhem Barruol, Jean-Paul Montagner. Identifying global seismic anisotropy patterns by correlating shear-wave splitting and surface-wave data. Physics of the Earth and Planetary Interiors, 2009, 176 (3-4), pp.198-212. 10.1016/j.pepi.2009.05.006 . hal00429396

\section{HAL Id: hal-00429396 https://hal.science/hal-00429396}

Submitted on 26 Oct 2016

HAL is a multi-disciplinary open access archive for the deposit and dissemination of scientific research documents, whether they are published or not. The documents may come from teaching and research institutions in France or abroad, or from public or private research centers.
L'archive ouverte pluridisciplinaire HAL, est destinée au dépôt et à la diffusion de documents scientifiques de niveau recherche, publiés ou non, émanant des établissements d'enseignement et de recherche français ou étrangers, des laboratoires publics ou privés. 


\title{
Identifying global seismic anisotropy patterns by correlating shear-wave splitting and surface-wave data
}

\author{
Andreas Wüstefeld ${ }^{\mathrm{a}, *}$, Götz Bokelmann ${ }^{\mathrm{a}}$, Guilhem Barruol ${ }^{\mathrm{a}}$, Jean-Paul Montagner ${ }^{\mathrm{b}}$ \\ a Université Montpellier II, CNRS, Géosciences Montpellier, F-34095 Montpellier cedex 5, France \\ ${ }^{\mathrm{b}}$ Institut de Physique du Globe de Paris, 4 place Jussieu, Case 89, 75005 Paris, France
}

\begin{abstract}
A B S T R A C T
We compare a global compilation of shear-wave splitting measurements with azimuthal seismic anisotropy parameters inferred from surface-wave tomography. The currently available splitting dataset is taken from a novel comprehensive collection of available publications that is updated interactively online. The comparison between the two types of data is made by calculating predicted splitting parameters from the anisotropic tomography model. Comparing these predicted splitting parameters with the observed ones, we find a considerable correlation between the two datasets at global scale. This result is noteworthy, since such correlation did not seem to exist in previous studies. The spatial resolution associated with the two types of methods is rather different. While surface waves have good vertical resolution and poor lateral resolution of several hundreds of kilometers, SKS splitting measurements have good lateral, but poor vertical resolution. The correlation can be understood in light of recent propositions that anisotropy seen by SKS splitting constrains mostly the upper mantle, and therefore a similar depth region as surface waves. The correlation also confirms the generally good quality of the shear-wave measurements, as well as that of the anisotropic tomography model.
\end{abstract}

\section{Introduction}

Seismic waves are arguably the most powerful geophysical tools to investigate the Earth's deep interior. Anisotropy is one of the many material properties that affect seismic wave propagation. It manifests itself as a dependence of wave speed on direction. Such anisotropy can be caused by structural variability, e.g., thin layers of alternating elastic properties (Backus, 1962) or fluidfilled cracks (Crampin, 1984; Kendall et al., 2006). A second origin which is widely accepted to dominate at mantle depths is the preferred orientation of anisotropic minerals by strain (e.g., Nicolas and Christensen, 1987). Olivine plays a major role in the anisotropy of the Earth's mantle because it represents the primary constituent of the upper mantle and is more anisotropic than the other minerals. At upper mantle conditions olivine deforms by dislocation-creep (Nicolas and Christensen, 1987), and therefore aligns its main crystallographic axes with respect to structural directions (lineation, pole of the foliation), therefore producing a large-scale anisotropy detectable by seismic waves that is correlated with the geometry of strain in the upper mantle. Identifying the orientation of seismic anisotropy and its strength can thus help to constrain deforma-

\footnotetext{
* Corresponding author. Present address: Department of Earth Sciences, University of Bristol, BS8 1RJ, United Kingdom. Fax: +44 1179253385.

E-mail address: andy.wuestefeld@bristol.ac.uk (A. Wüstefeld).
}

tion at depth. Comparing seismic anisotropy with other observables such as gravitation and topography (Simons and van der Hilst, 2003) or the magnetic anomalies (Bokelmann and Wüstefeld, 2009; Wüstefeld et al., in press) is helpful for understanding tectonic processes acting within the Earth, both, ancient ones recorded within the lithosphere, and more recent ones in the asthenosphere.

Hess (1964) was the first to measure azimuthal anisotropy from Pn travel-time variations beneath the northern Pacific and to interpret these variations in terms of mantle flow induced by sea-floor spreading. Since these pioneering works, a variety of techniques have been proposed for detecting seismic anisotropy. These include relative P-wave delay times (e.g., Babuska et al., 1984; Bokelmann, 2002a,b), P-wave polarization (Bokelmann, 1995; Schulte-Pelkum et al., 2001; Schulte-Pelkum and Blackman, 2003; Fontaine et al., 2009), shear-wave splitting (for references see below) and radial and azimuthal anisotropic surface-wave tomography (e.g., Montagner, 1986; Nishimura and Forsyth, 1988; Montagner and Tanimoto, 1991).

The most direct evidence of seismic anisotropy is the splitting of shear waves. Anisotropic media are indeed birefringent, splitting the incoming shear waves into two perpendicularly polarized waves that propagate at different velocities. At the Earth's surface, it is therefore possible to quantify anisotropy by measuring the two splitting parameters $\delta t$ and $\Phi$. The difference in arrival times $(\delta t)$ between the two split shear waves (Fig. 1) depends on both the anisotropy strength and the length of the travel path through the 


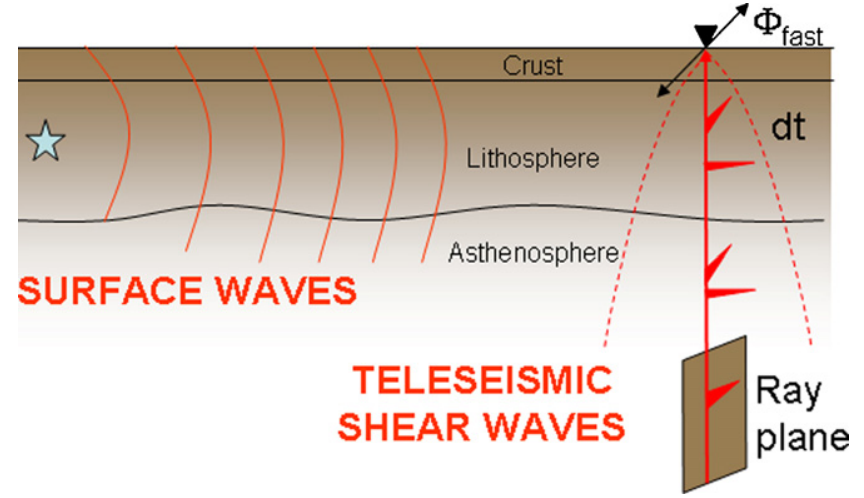

Fig. 1. Paths and spatial resolution associated with teleseismic (SKS) shear waves and surface waves. Surface waves propagate along the surface of the Earth, while wave paths of teleseismic shear waves are nearly vertical. For the latter, there is a progressive time delay between the two (split) shear waves on the path toward the station at the Earth's surface.

anisotropic medium. The azimuth $\Phi$ of the fast split shear wave polarization planes is related to the orientation of the anisotropic structure. Initially limited to direct $\mathrm{S}$ waves from local events (Ando et al., 1980), the technique is now widely adopted for core-transiting phases such as SKS, SKKS, and PKS (e.g., Vinnik et al., 1984, 1989; Silver and Chan, 1991; see Savage, 1999 and Fouch and Rondenay, 2006 for a review). Travelling on nearly vertical paths, teleseismic shear waves provide measurements of anisotropy beneath a seismic station with a relatively good lateral resolution of few tens of kilometers (Fresnel-zone width) but with poor vertical resolution. The teleseismic shear-wave splitting technique has become popular in the last decades for performing anisotropy measurements that help revealing present or past mantle deformation processes. This technique has been widely applied in several geologic settings: Subduction zones (e.g., Levin et al., 2004; Margheriti et al., 2003; Nakajima and Hasegawa, 2004), rifts (e.g., Kendall, 1994; Gao et al., 1997; Walker et al., 2004a,b; Kendall et al., 2005), hotspots (e.g., Barruol and Granet, 2002; Walker et al., 2001, 2005), oceanic islands (e.g., Behn et al., 2004; Fontaine et al., 2005, 2007), orogens (e.g., Barruol et al., 1998; Flesch et al., 2005) and stable continental environments (e.g., Fouch et al., 2000; Heintz and Kennett, 2005; Fouch and Rondenay, 2006; Assumpcao et al., 2006).

Azimuthal anisotropy was initially deduced from surface waves by Forsyth (1975), then by Nishimura and Forsyth (1988) in Pacific and by Montagner and Tanimoto (1991) at global scale. The ever-growing dataset of seismic stations and recordings have allowed, over the years, to significantly improve spatial resolution of azimuthally anisotropic tomographic models (e.g., Trampert and Woodhouse, 2003; Smith et al., 2004; Debayle et al., 2005; Maggi et al., 2006). By using the surface-wave (Rayleigh and Love) frequency dependence on their penetration depth, surface-wave tomography provides a relatively good vertical resolution of velocities and anisotropy down to the transition zone although the lateral resolution is relatively poor, generally not better than several hundreds of kilometres. In addition to the good vertical resolution, surfacewave tomography has the advantage of providing a continuous and global-scale coverage of azimuthal anisotropy, except in poorly covered areas. This is in sharp contrast to the resolution of teleseismic shear-wave splitting measurements which provide localized measures of anisotropy directly beneath a seismic station.

Given the constraints on deformation within the Earth that seismic anisotropy offers, there is much interest in understanding the origin of that anisotropy. Comparing observed fast directions with absolute plate motion directions is of interest (e.g., Vinnik et al., 1984; Silver and Chan, 1991; Montagner, 1994), since anisotropy in the asthenosphere, if caused by relative motion between plates and deeper interior of the Earth, should have fast directions parallel to plate motion. On the other hand, fossil anisotropy in the lithosphere does not need to show a correlation with current plate motion directions. It is also of interest to compare seismic anisotropy with predicted seismic anisotropy from flow calculations that have become available in recent years. That has been done at regional scale (Griot et al., 1998; Fouch et al., 2000; Becker et al., 2006), and also at global scale (Behn et al., 2004; Becker et al., 2007; Conrad et al., 2007)

This study addresses the question whether shear-wave splitting observations and surface-wave azimuthal anisotropy can be used interchangeably for the comparison with flow models. The different spatial resolution of the two types of data may result in significant differences: surface waves offer vertical resolution, while body waves offer lateral resolution. Furthermore, shear-wave splitting observations have mostly been made on continents (Fig. 1), whereas surface-wave models offer some resolution at all places of the Earth's surface, although poor ray coverage may result in weak constrains in some regions. A further complication for comparing the two datasets arises from the fact that the anisotropy is mainly characterized by two parameters, fast orientation and strength. A good coherence in one parameter does not necessarily means a good coherence in the other.

So far, there have been only few attempts to directly relate bodywave and surface-wave anisotropy. Because the two techniques sample the anisotropy along vertical and horizontal propagation directions, respectively, the results cannot be compared directly. Montagner et al. (2000) proposed to predict splitting parameters from a multi-layer anisotropic surface-wave model. That study has suggested reasonable correlation at regional scale in some regions, but at global scale there did not appear to be a clear correlation. The possibility was discussed that the spatial resolution of the two techniques is perhaps too different to allow realistic comparisons.

In this paper we follow the approach of Montagner et al. (2000), and we study the relation between anisotropy measures from shear-wave splitting and surface-wave models at global scale, as well as for a few selected key regions. We will in fact show that there is indeed a correlation at global scale, and discuss its implications. In the first part of the paper, we present the new shear-wave splitting dataset. In the second part we present the prediction of splitting measurements obtained from recent surface-wave tomography and in the third part, we compare the observed splitting data with the predicted parameters.

\section{World-wide shear-wave splitting results}

Over the past decades, a large number of shear-wave splitting studies have been published. Some of these studies have analyzed sets of globally distributed stations (e.g., Silver, 1996; Barruol and Hoffmann, 1999), while most focused on regional networks of stations, providing detailed knowledge on specific areas. Ever-larger temporary seismic arrays (e.g., USArray) and long-running permanent stations make the available shear-wave splitting dataset grow rapidly, and the need for a central depository for all available splitting measurements has been evoked (e.g., Fouch and Rondenay, 2006). Evans et al. (2006) present a shear wave splitting database, where they re-calculated available broadband stations. Our approach is different from that. In order to make all the published splitting data easily available in a homogeneous format, we developed an interactive database. The main features of this shear-wave splitting database are that the user may: (i) enter new splitting data via a web interface, (ii) search the database for a specific station or within a region, (iii) download the whole splitting parameters and corresponding bibliographic references and (iv) visualize the database, e.g., through GoogleEarth. Such an 


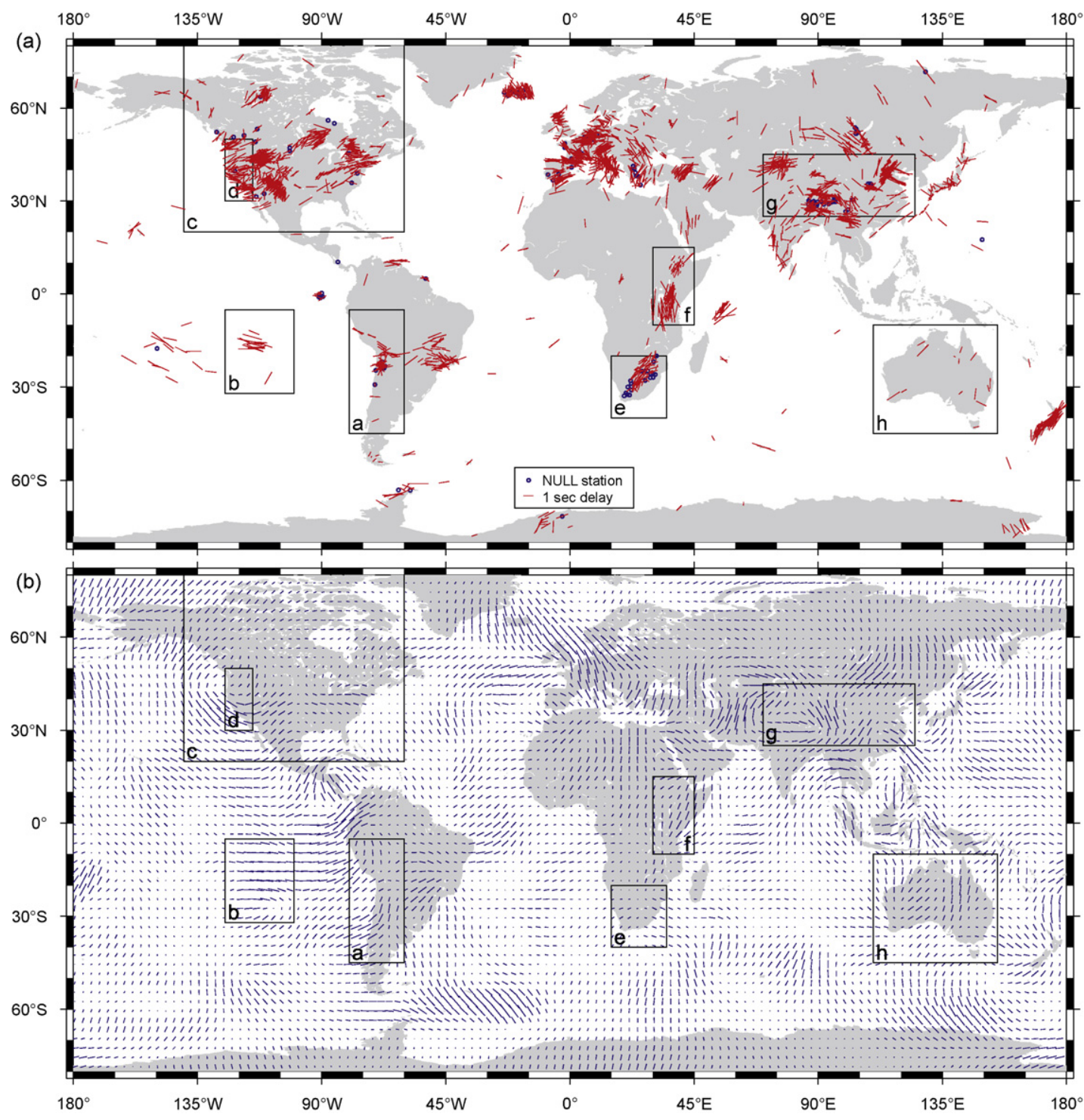

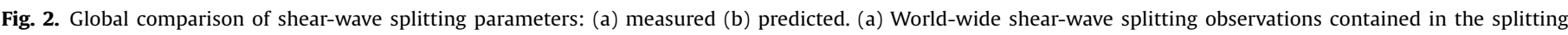

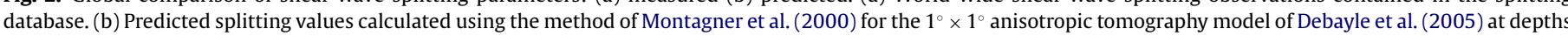
between 50 and $500 \mathrm{~km}$. Values are displayed on a $3^{\circ} \times 3^{\circ}$ grid. The regions which are analyzed in further detail in the text are marked (a-h).

approach ensures that results of individual studies will be taken into account by the community, as users of splitting data will always find the most "up-to-date" information. This database is available on the "Geosciences Montpellier" website at the address http://www.gm.univ-montp2.fr/splitting/DB.

As of June 2008, the database contains 2566 entries from 133 referenced studies (see Fig. 2a). Note that the database is a collection of the work of various authors over many years, using a broad range of filters and possibly quality control factors. The global splitting delay times show an approximately log-normal distribution with most values between 0.4 and $1.4 \mathrm{~s}$ and a maximum at $1 \mathrm{~s}$ (Fig. 3a and $b$ ). This distribution is in agreement with earlier studies, e.g., that of Silver (1996). Petrophysical analyses of upper mantle rocks sampled in orogenic or ophiolite peridotite massifs, or as kimberlite or basalt xenoliths suggest that such a mean delay time requires a 100-150 km thick anisotropic layer (Mainprice and Silver, 1993; Ben Ismail and Mainprice, 1998; Mainprice et al., 2000; Ben-Ismail et al., 2001). We note that fast-axis orientations prefer $\mathrm{E}-\mathrm{W}$ orientations, which are interesting in the light of speculations of uniform global plate motion relative to the underlying mantle (Doglioni, 1994; Steinberger and O'Connel, 1998; Doglioni et al., 2003). However, these statistics have to be considered with care, for two reasons: (i) the ocean-continent discrepancy: most splitting data originated from continents, where the azimuth may be dominated by frozenin lithospheric anisotropy. Only a small amount of splitting data originated from oceanic environments where one could expect to observe present-day processes related to asthenospheric flow. (ii) Seismic stations are not evenly distributed worldwide. Temporary experiments generally gather many instruments in a small area (e.g., Barruol et al., 1998; Walker et al., 2005; Flesch et al., 2005), which may cause a bias in statistical analyses. Furthermore, the different continents are not equally well sampled, and there is indeed an over-representation of North America and Western Europe in the dataset.

\section{Predicting shear-wave splitting parameters from surface-wave data}

Montagner et al. (2000) developed a method to predict splitting parameters from surface-wave anisotropy results. Their approach is not unlike that of several earlier studies that discuss the effect of multiple anisotropic layers on the effective splitting parame- 

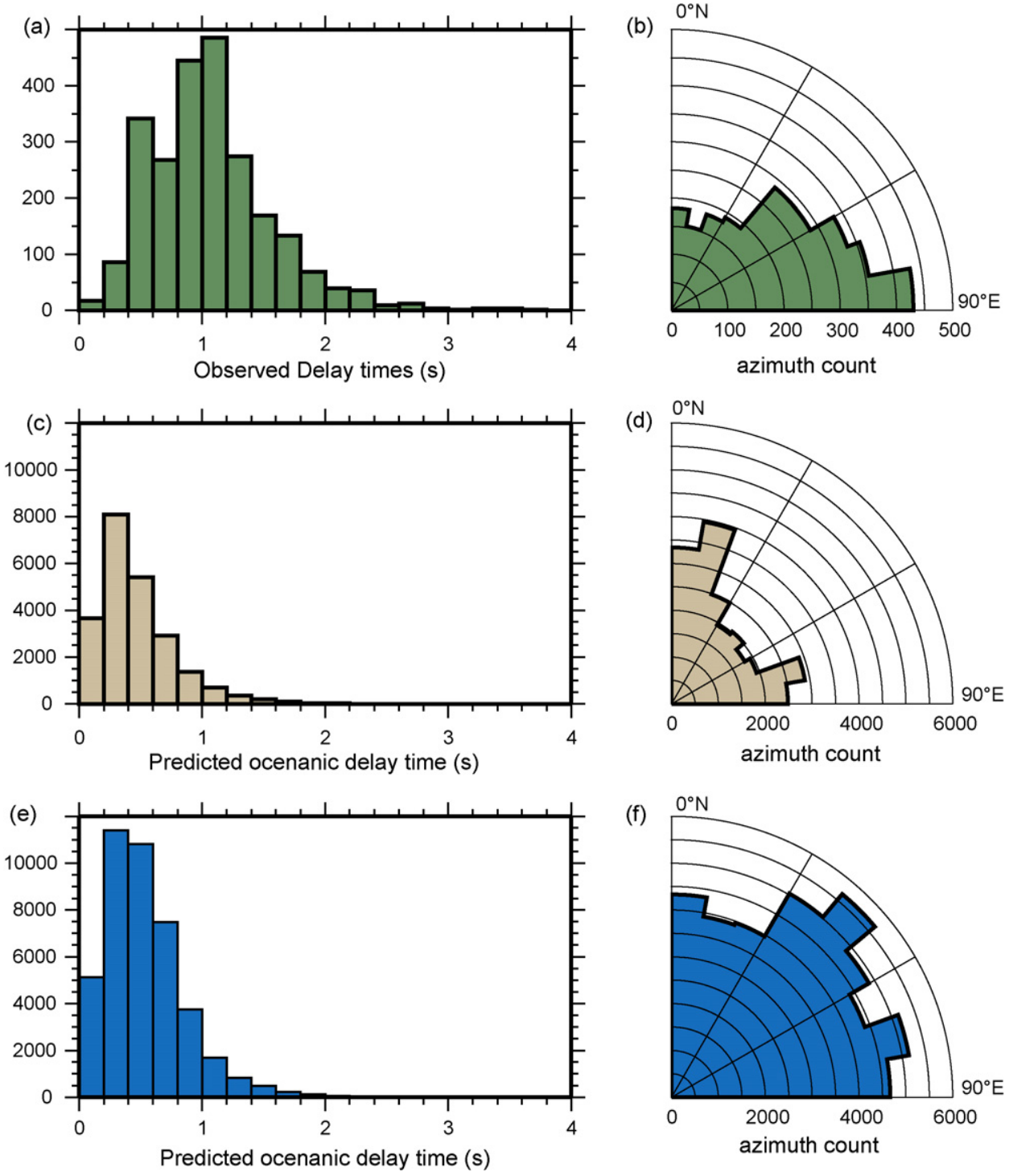

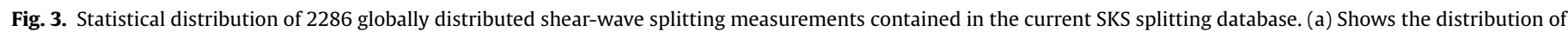

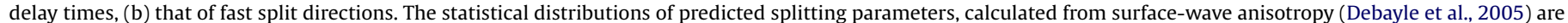
presented separately for continents (c, d) and oceans (e, f). See text for discussion.

ters (Silver and Savage, 1994; Wolfe and Silver, 1998; Rümpker and Silver, 1998; Saltzer et al., 2000). The fast axis $\Phi$ as well as the delay time $\delta t$ of a vertically propagating SKS phase that results from a (weak) anisotropic layer is related to the elastic parameters $G_{\mathrm{S}}=\mathrm{C}_{45}$, $G_{\mathrm{C}}=1 / 2\left(C_{55}-C_{44}\right)$, and $L=1 / 2\left(C_{44}+C_{55}\right)$ that can be obtained from surface-wave studies (Montagner, 1986). This can be generalized for multiple layers. Montagner et al. (2000) have proposed a first-order expansion that is valid at periods larger than 10 s, e.g., for SKS and SKKS waves. Under that assumption, splitting delay and fast direction can be predicted by a simple integration along the (assumed vertical) ray path, as

$$
\begin{aligned}
& \mathrm{d} \bar{t}=\sqrt{\left(\int_{0}^{a} \sqrt{\frac{\rho}{L} \frac{G_{\mathrm{c}}}{L}} \mathrm{~d} z\right)^{2}+\left(\int_{0}^{a} \sqrt{\frac{\rho}{L} \frac{G_{\mathrm{s}}}{L}} \mathrm{~d} z\right)^{2}} \\
& \bar{\phi}_{\mathrm{fast}}=\frac{1}{2} \arctan \left(\frac{\int_{0}^{a} \sqrt{(\rho / L)\left(G_{\mathrm{s}} / L\right) \mathrm{d} z}}{\int_{0}^{a}(\rho / L)\left(G_{\mathrm{c}} / L\right) \mathrm{d} z}\right)
\end{aligned}
$$

where $a$ corresponds to the maximum depth extent of the tomographic model and $\rho$ is the density of each layer. In the following we will use the global tomographic model of Debayle et al. (2005). Fig. 2b shows predicted shear-wave splitting for that model, integrating from 500 to $50 \mathrm{~km}$ depth (thus excluding the negligible influence of the crust).

Debayle et al. (2005) have used observations of fundamental and higher-mode Rayleigh waves, and among the 100779 ray paths, they include many short epicentre-station paths, which give particularly strong constraints. The inversion has used a spatially variable cell size determined using Voronoi tessellation, and the smallest cells have sizes of about $200 \mathrm{~km}$. Since anisotropic and isotropic variations often occur together, it is not likely that the very small variations are resolved. Therefore, the tomographic inversion has also imposed a spatial smoothness constraint via a Gaussian correlation function with standard deviation of $400 \mathrm{~km}$. It is clear that resolution must vary strongly with location along the Earth's surface, due to the variable ray coverage. In places where the coverage is particularly good, resolution will be better, but it is not quite clear what the resolution limit is. In principle, a Voronoi technique is well-adapted for optimally extracting information in this situation. In any case, a lower bound on resolution is imposed 

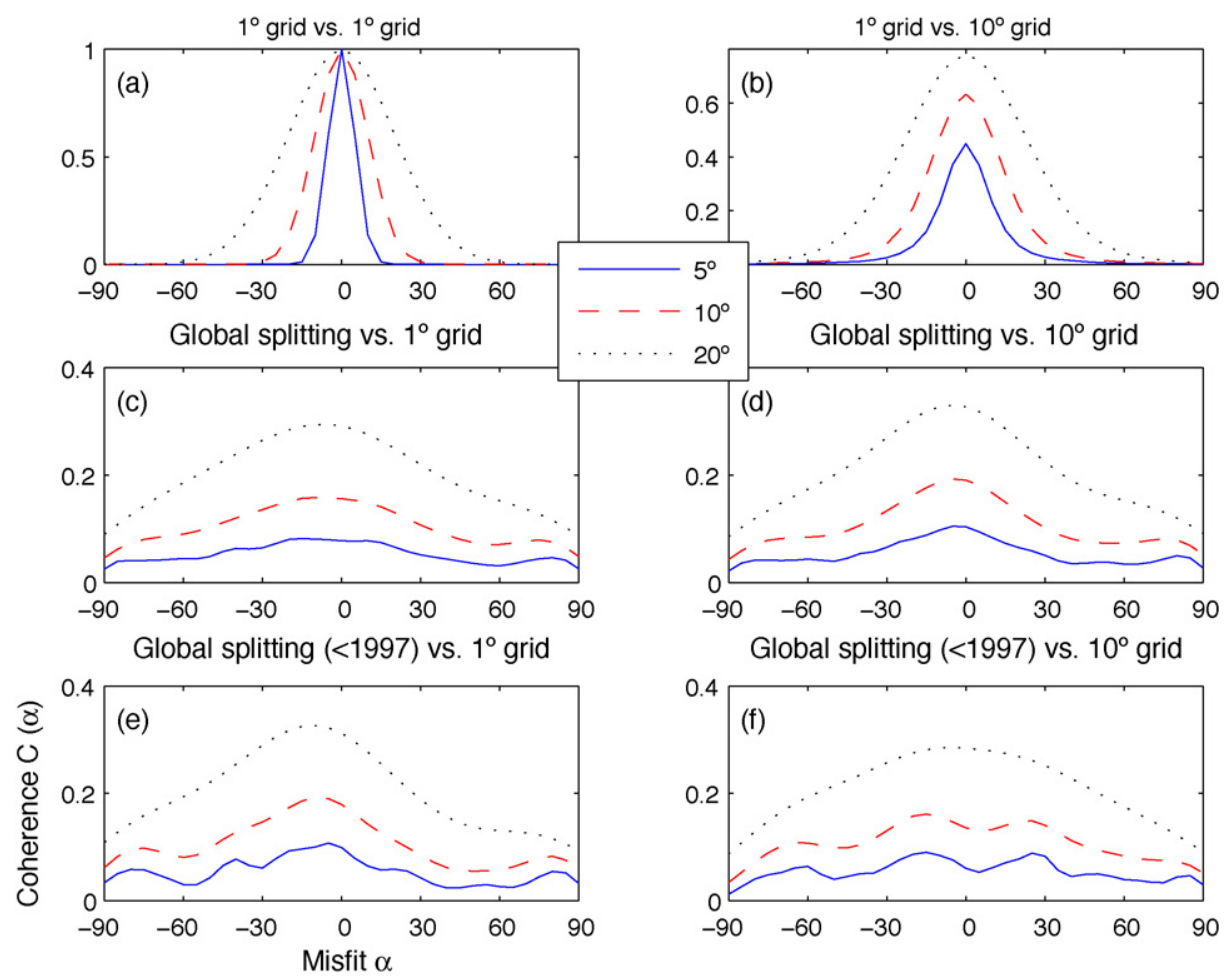

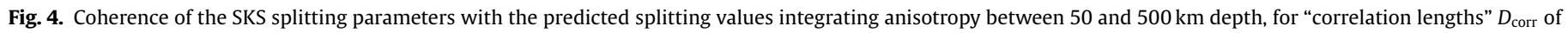

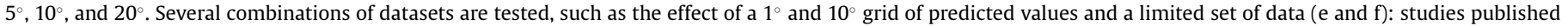
before 1997, corresponding to dataset of Silver (1996). See text for discussion.

by the smoothness constraint corresponding to length scales of $400 \mathrm{~km}$.

Fig. 3c-f presents the statistical distribution of the predicted splitting parameters. The delay times range between 0 and $2 \mathrm{~s}$, with a maximum of the distribution around $0.5 \mathrm{~s}$, for both continental and oceanic environments. The predicted splitting delay times are thus systematically smaller delay than the observed ones (Fig. 3a and b). Potential causes for this bias may be (i) the damping that is necessarily applied during the surface-wave inversion, leading to an underestimation of parameters, (ii) an underestimation of true lateral variations due to an insufficient lateral resolution of surface waves and/or (iii) incompatibilities between the assumptions of anisotropy systems inherent to both methods. We choose to show the angular distribution separately for continental (Fig. 3c and d) and oceanic regions (Fig. 3e and f). For oceanic environments, the predicted splitting orientations display hardly any azimuthal preference on a global scale. However, for continental areas there are two maxima of predicted fast directions, a stronger one in $\mathrm{N}-\mathrm{S}$ direction, and a weaker one in $\mathrm{E}-\mathrm{W}$ direction. The $\mathrm{N}-\mathrm{S}$ predicted fast directions appear primarily in Africa, north-east Asia, and Australia (Fig. 2b), where station coverage for observed splitting measurements is poor. Such a discrepancy between predicted and observed fast split direction statistics could therefore be related to the extremely uneven station coverage present in the splitting database. However, at least for Africa, that for body waves, and it therefore does not serve to confirm this as a continental feature at the largest scale.

\section{Comparing observed and predicted SKS splitting}

The two datasets we compare have rather different distribution on the Earth's surface. While the splitting parameters are obtained at unevenly distributed seismic stations (Fig. 2a), the predicted splitting values from the surface-wave model of Debayle et al. (2005) are evenly distributed on a $1^{\circ} \times 1^{\circ}$ grid (Fig. 2b). Comparing the two datasets therefore requires interpolation. Interpolating sparse vectorial data as splitting measurements onto a regular grid is possible (Bird and Li, 1996; Lucente et al., 2006), but to avoid stability problems due to the different spatial support, we prefer to follow the approach proposed by Montagner et al. (2000), i.e., we linearly interpolate the regular grid of the predicted anisotropy parameters to the location of each splitting measurement.

The correlation between the observed and predicted datasets is then obtained by using an adapted form of the coherence function initially defined by Griot et al. (1998). This mathematical function quantifies the correlation between two vectorial data sets on a sphere (co-latitude $\Theta$, longitude $\Psi$ ) by taking into account the two anisotropy parameter pairs $\left(\Phi_{1}, \delta t_{1} ; \Phi_{2}, \delta t_{2}\right)$. Since each parameter pair corresponds to a phase and amplitude, a natural form of the coherence between two continuous fields on the sphere is

$$
C(\alpha)=\frac{\int_{\Theta} \int_{\Psi}\left\{\mathrm{d} t_{1}(\Theta, \Psi) \sin \Theta \mathrm{d} t_{2}(\Theta, \Psi) \sin \Theta \exp \left(-\left(\left(\phi_{1}(\Theta, \Psi)-\phi_{2}(\Theta, \Psi)+\alpha\right)^{2} /\left(2 D_{\text {corr }}^{2}\right)\right)\right)\right\} \mathrm{d} \Theta \mathrm{d} \Psi}{\sqrt{\int_{\Theta} \int_{\Psi} \mathrm{d} t_{1}(\Theta, \Psi)^{2} \sin ^{2} \Theta \mathrm{d} \Theta \mathrm{d} \Psi} \sqrt{\int_{\Theta} \int_{\Psi} \mathrm{d} t_{2}(\Theta, \Psi)^{2} \sin ^{2} \Theta \mathrm{d} \Theta \mathrm{d} \Psi}}
$$

the $\mathrm{N}-\mathrm{S}$ orientation is in accordance with recent surface-wave tomographic models (Sebai et al., 2006; Montagner et al., 2007). The E-W maximum is much less pronounced for surface waves than
The phases (fast directions) enter through an exponential form that is normalized by a "correlation factor" $D_{\text {corr }}$. This formula does not require an alignment of the two sets of fast axes. The test orientation $\alpha$ can vary between $-90^{\circ}$ and $+90^{\circ}$ and allows testing for 
an angular bias between the two datasets. The normalization in the conventional fashion ensures that the coherence varies between 0 (uncorrelated) and 1 (perfect correlation). An anti-correlation between the fast axes would show up as a peak at $\pm 90^{\circ}$.

If $C(\alpha)$ is represented by a horizontal line, the two models are uncorrelated. A Gaussian shape of $C(\alpha)$ indicates a certain coherence, with the location of the peak corresponding to the mean rotation between the models. Fig. 4a illustrates this by comparing the $1^{\circ} \times 1^{\circ}$ predicted splitting dataset with itself. As expected, this results in a Gaussian distribution with a maximum value of 1 oriented at $0^{\circ}$. Fig. $4 \mathrm{~b}$ shows the coherence of the predicted splitting data on a $1^{\circ}$ grid with that of a $10^{\circ}$ grid. Maximum values are considerably smaller than 1 now, and the distributions are much wider, reflecting the added variance from the interpolation using the $10^{\circ}$ grid. In fact, there is much variation of predicted fast directions in Fig. $2 \mathrm{~b}$, at scales below $10^{\circ}$.

\subsection{Global correlation of splitting parameters}

Montagner et al. (2000) compared splitting parameters as predicted by a global anisotropic tomography model (Montagner and Tanimoto, 1991) with the shear-wave splitting results compiled by Silver (1996). The results suggested a fairly good coherence at regional scale (for instance in the Western United States and in Central Asia), but no clear coherence at global scale. The authors have attributed the latter to the different depth and lateral sensitivity in both datasets. Surface waves are best resolved in oceanic environment, where large-scale structures are expected but where station coverage and therefore shear-wave splitting measurements are sparsely distributed in that environment. In contrast, shearwave splitting has a relatively good lateral resolution and may evidence short-scale variations in upper mantle structures beneath the continents that are hardly visible from surface-wave analyses. The authors also suggested that the usually-performed single-layer inversion for splitting parameters may represent an oversimplification that contributes to the missing global correlation.

Fig. $4 \mathrm{c}$ and $\mathrm{d}$ show the coherence of predicted splitting from the model of Debayle et al. (2005), integrated between 50 and $500 \mathrm{~km}$ depth, with the splitting database, taking into account the entire database using gridding sizes of $1^{\circ}$ and $10^{\circ}$, for the correlation lengths used previously $\left(D_{\text {corr }}=5^{\circ}, 10^{\circ}\right.$ or $\left.20^{\circ}\right)$. The coherence is slightly broader for the $10^{\circ}$ grid (Fig. 4d) than for the $1^{\circ}$ grid (Fig. 4c). However, both comparisons give a rather good correlation of available splitting data and anisotropic surface-wave model, with a maximum centred near $0^{\circ}$ misfit. This indicates that the available splitting database sufficiently covers the globe, as it is insensitive to the resolution of the surface-wave model.

In the former study, Montagner et al. (2000) used the anisotropic surface-wave model of Montagner and Tanimoto (1991) and the splitting data collection of Silver (1996). The global coherence was found to show a local minimum at $0^{\circ}$ misfit, with local maxima on both sides. We were able to roughly reproduce this behaviour by incorporating only the splitting measurements available before 1997 (Fig. 4e). Montagner et al. (2000) concluded that there is no global correlation. In fact, Fig. $4 d-f$ suggest that the absence of correlation in that study was apparently an effect of insufficient splitting data coverage and limited spatial resolution in available surface-wave models at the time. Since Fresnel zones of the commonly used SKS waves are of the order of $100 \mathrm{~km}$ at upper mantle depths, and since splitting parameters vary at these scale length (Fig. 2a), averaging azimuthal anisotropy at scale larger than $10^{\circ}$ introduce a too large smoothing to preserve a good coherence between the body-wave pattern and the large-scale surface-wave pattern.

The higher correlation of the new global set (Fig. 4c) in comparison to sub-dataset of Silver (1996) (Fig. 4e) may on the other hand reflect the numerous regional studies performed after 1996, that concentrate a large number of stations in relatively small areas, e.g., in the Eifel region (Walker et al., 2005), and the Pyrenees (Barruol et al., 1998). This leads to regional biases. The difference suggests that we should try to eliminate the regional biases if possible, or at least eliminate the effect of the spatially varying data density where we have data. So far, all data points enter equally into the coherence, and local studies with dense station coverage will thus have a stronger effect on the coherence than sparsely instrumented areas. We address this problem by gridding the splitting data. However, standard interpolation procedures are inappropriate when interpolating sparse directional data on a sphere (Bird and $\mathrm{Li}, 1996)$. One approach to solve this problem may be by using Voronoi cells, similar to the method of Debayle et al. (2005) or Larmat et al. (2006). In this study, however, we follow a different approach: To account for both the amplitude and orientation of anisotropy we separate amplitude (delay time) and orientation (fast direction). The delay time is gridded using a standard cubic spline interpolation to give a map of gridded delay times $T$. The directional component of anisotropy is computed using an algorithm that has already been successfully applied to global stress data (Müller et al., 2003). The gridding algorithm is based on Watson (1985) and extended by a distance weighting (Wehrle, 1998). For a series of unit vectors $\vec{y}$, given at positions $\vec{x}$, Watson (1985) proposes a technique that searches for a 'predictor' function $\vec{f}(\vec{x})$ that describes the vector field parallel (or anti-parallel) to $\vec{y}$. This is achieved by maximising the (quadratic) scalar product $P=\left\langle\vec{f}\left(\vec{x}_{i}\right)^{T} \vec{y}_{i}\right\rangle^{2}$. Furthermore, to be smooth, the (quadratic) scalar product of two neighbouring functions $N=\left\langle\vec{f}\left(\vec{x}_{i}\right)^{T} \vec{y}_{j}\right\rangle^{2}$ must be maximum as well. The resulting gridded vector field is thus the maximum of the following function $K(f)$ :

$K(f)=\sum_{i=1}^{n}\left(\operatorname{Pd}\left(\vec{x}_{i}, \vec{x}_{i}\right)+\lambda \sum_{j=1, j \neq i} \operatorname{Nd}\left(\vec{x}_{j}, \vec{x}_{i}\right)\right)$

As mentioned, the $P$-term achieves optimum fitting of the data, the $N$-term controls the smoothness of the resulting field. The weighting factor $\lambda$ lambda thus controls the relative influence of the data fidelity and smoothness, respectively. The function $\mathrm{d}\left(x_{i}\right.$, $x_{j}$ ) expresses the distance weighting of point $x_{j}$ at $x_{i}$ within a search radius $R$ (Wehrle, 1998). The interpolated splitting "vector field" is then the linear combination of the gridded splitting amplitude and $K(f)$, calculated at the locations $\vec{s}_{i}$. These coincide with the grid points of the tomographic model and thus the location of the predicted splitting parameters.

$V=\left.\left.T\right|_{\vec{S}} K(f)\right|_{\vec{S}}$

Fig. 5 shows an example result of that gridding for $R=600 \mathrm{~km}$ and $\lambda=5$ on a $3^{\circ} \times 3^{\circ}$ grid. Null measurements, though important to constrain fast directions at individual stations (Wüstefeld and Bokelmann, 2007), are not taken into account.

Similar to Fig. 4, we calculate the coherence functions of the predicted splitting with these smoothed global datasets, to ascertain that the correlation between observed and predicted splitting as described in the previous section, is not an artefact of the rather heterogeneous data density. If the correlation is real, this helps to define the inherent lateral resolvability of anisotropy by the used surface-wave model.

The results for various parameter combinations of $R$ and $\lambda$ are presented in Fig. $6 a\left(D_{\text {corr }}\right.$ is fixed to $\left.10^{\circ}\right)$. For all tests, there is a maximum near $0^{\circ}$, suggesting that there is indeed a correlation also for the gridded data, similar to the global correlation found previously (Fig. 4). The correlation between the two datasets is therefore not an artefact of the uneven sampling. 


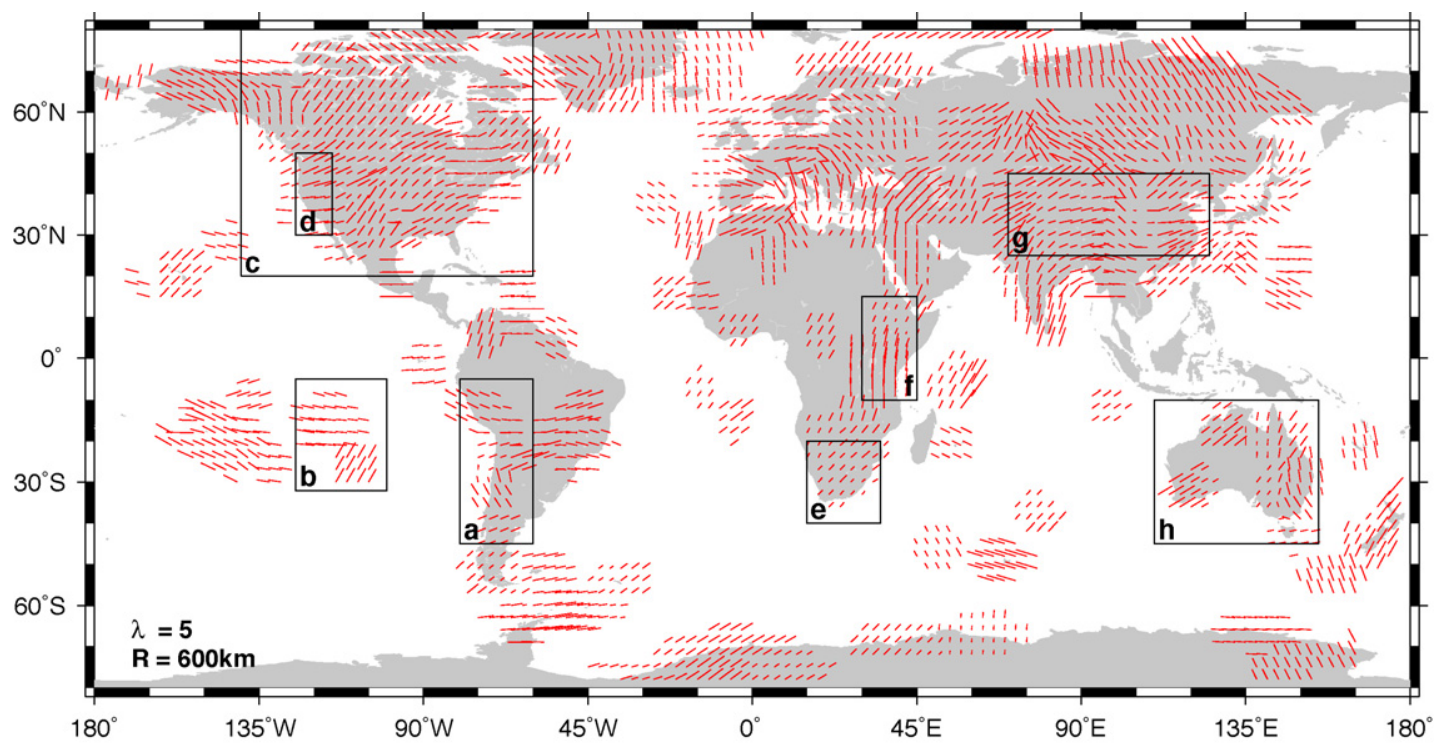

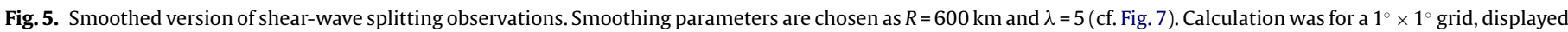
on a $3^{\circ} \times 3^{\circ}$ grid.

Fig. $6 \mathrm{~b}$ shows the dependence of the coherence value at $0^{\circ}$ on search radius for various $\lambda$. Interestingly, the coherence decreases clearly below $R=400 \mathrm{~km}$ while it stays more or less constant between 400 and $1000 \mathrm{~km}$. Below $R=400 \mathrm{~km}$, the coherence shows a weak dependence on smoothing parameter $\lambda$. This is as expected, since the effect of $\lambda$ must be somewhat similar to that of the search radius. Thus, the decrease of coherence below $R=400 \mathrm{~km}$ also manifests itself in the $\lambda$ values. A peak in coherence is obtained for strong smoothing with $\lambda=10$ and 50 at search radii of $R=400 \mathrm{~km}$. Moreover, a plateau of relatively good coherence is found for $\lambda=5$ and $R$ between 600 and $700 \mathrm{~km}$.

Fig. $6 c$ and $d$ are similar to Fig. $6 a$ and b, but the order of each parameter $\left(\Phi_{1}, \delta t_{1} ; \Phi_{2}, \delta t_{2}\right)$ has been randomised. In such random test any spatial coherence should be eliminated, unless there is an inherent correlation, due to a non-random data distribution. Comparing Fig. 6c with Fig. 6a we note that coherence indeed drops sharply, indicating that the correlation observed in Fig. 6a is indeed real. The weak residual coherence in Fig. $3 \mathrm{~b}$ thus shows the artefact of the non-uniform distribution of splitting fast directions.

\subsection{Regional correlation of splitting parameters}

The previous section showed that anisotropy as determined from surface waves and those from body waves show similar results on a global scale, though both methods sample the Earth at different scales. In this section we discuss several regional subsets of different tectonic background. Montagner et al. (2000) point out that several regional subsets have a rather good coherence despite the poor global coherence obtained in their earlier study. They relate that partially to an increased resolution of regional tomographic models used. We limit our comparison here to regional subsets of the global model. Regional tomographic models might provide higher
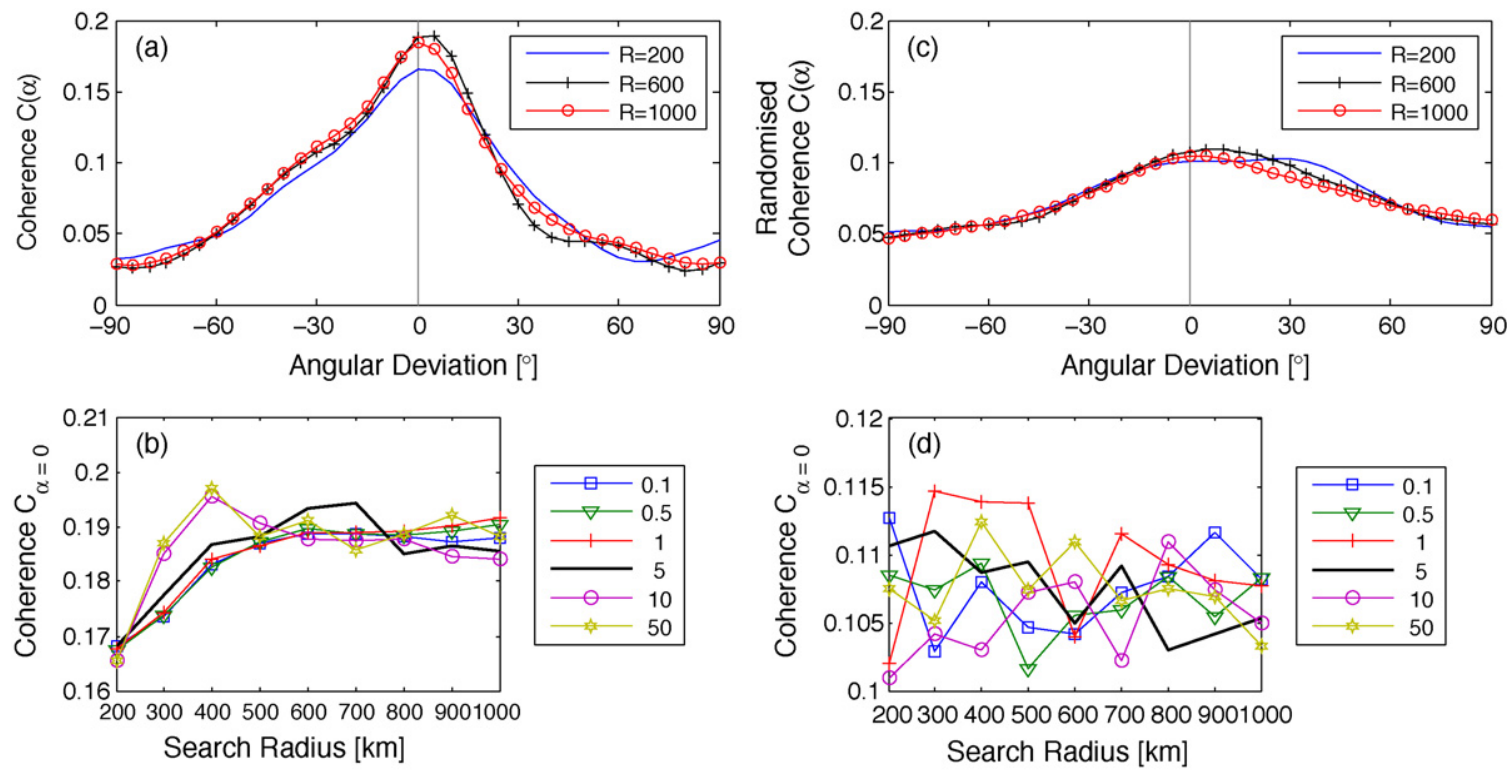

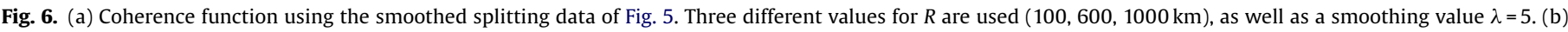

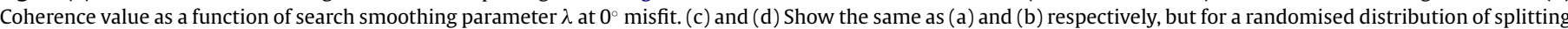
parameters to test for inherent correlation of the two models. Note the much lower amplitude of correlation in (c) and the random variation in (d). 

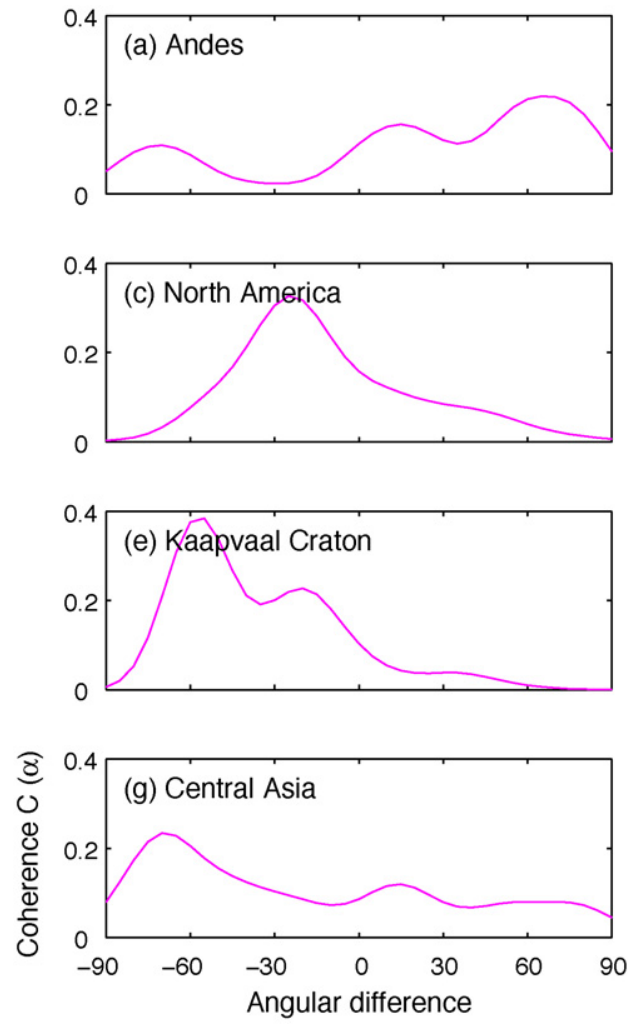
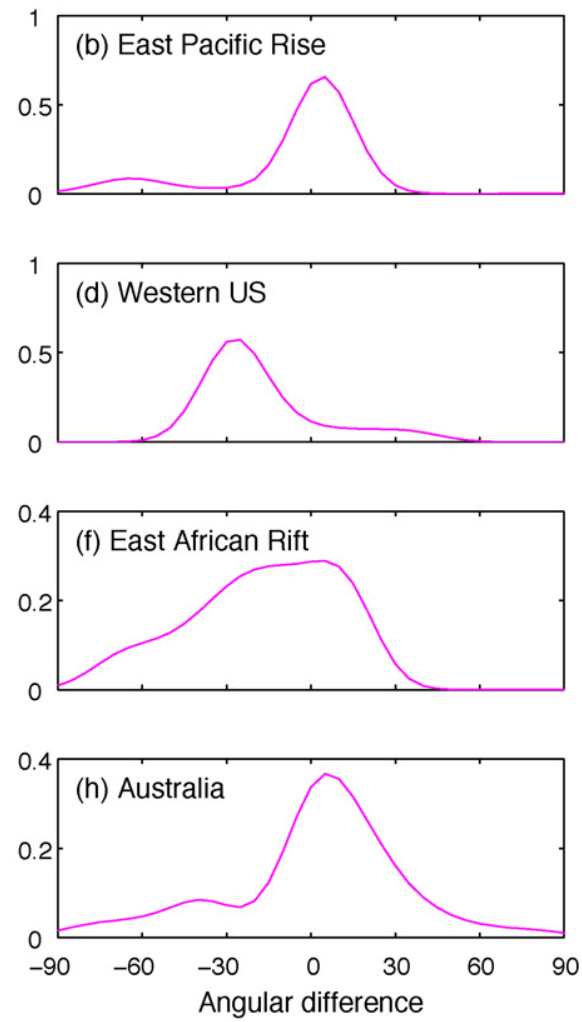

Fig. 7. Correlation of the smoothed splitting parameters (similar to Fig. 4), for individual regions shown in Fig. 5.

resolution, yet a detailed comparison of all available models would be beyond the scope of this study. Fig. 7 illustrates the coherence function for several regional subsets in different tectonic settings (subduction, rifts, volcanic islands, cratons). See Figs. 2 and 5 for locations. Generally, the coherence is very good, with a clear maximum centred close to $0^{\circ}$ misfit. Only the absolute value of that maximum varies between the regions. We attribute this to differences in the observed and predicted delay times, as we will discuss below.

Montagner (2002) selected Western United States and Central Asia for closer discussion. For consistency and comparison with that study we will briefly discuss the results of our new coherence study, and also present results for other selected regions and tectonic settings. Additional maps of test regions can be found in Appendix. This section shall provide an overview on coherences between the two datasets. For detailed interpretation of the anisotropy in the selected regions we kindly refer to the according publications.

\subsubsection{The Andes}

Several studies analyzed shear-wave splitting in the Andes and adjacent Nazca plate. Polet et al. (2000) argue that most significant contribution to splitting occurs below the slab, with a complex, spatially varying anisotropy pattern. Russo and Silver (1994) and Helffrich et al. (2002) propose that the large-scale pacific mantle flow pattern is deviated around the South American continent by roll-back of the Nazca slab.

The coherence between predicted and interpolated observed splitting is variable in this area, with poles at $-70^{\circ},+20^{\circ}$ and $+60^{\circ}$

(Figs. 7a and 10). This behaviour renders the complex interaction, sometimes at small scale, between subduction of oceanic plate and mountain range formation, both of which may cause different anisotropy orientations (Vauchez and Nicolas, 1991; Barruol et al., 1998; Kneller et al., 2007).

\subsubsection{The East Pacific Rise}

The coherence between predicted and interpolated observation of splitting is striking for stations in the vicinity of the East Pacific Rise (Figs. 7b and 11). These measurements come from the MELT and GLIMPSE Ocean Bottom Seismometers experiments (Wolfe and Solomon, 1998; Harmon et al., 2004). They proposed Lattice Preferred Orientation (LPO) of anisotropic minerals parallel to mantle flow trending normal to the spreading axis as main cause for splitting, as well as a deeper contribution of an asthenospheric return flow from the South Pacific superswell. This agreement between the fast split directions and the surface-wave anisotropy is not restricted to the ridge itself but is extending further West in the French Polynesia domain where Fontaine et al. (2007) evidenced a clear signature of the asthenospheric flow in the SKS splitting observations that also dominates within the surface-wave tomographies, both exhibiting dominant fast directions parallel to the plate motion direction. Further south, the EPR region also contains station RPN, located on the Easter Island Hot Spot, for which a multi-layer case has been proposed (Fontaine et al., 2007). The SKS anisotropy pattern observed at this station is clearly not the result of the ridge spreading alone and may likely result from the combination of spreading-related mantle flow and hotspot-related mantle upwelling. South and east of station RPN, although both the station coverage and resolution of the surfacewave model is too small to confidently relate this behaviour to mantle upwelling, the predicted and interpolated splitting coincide rather well, whereas towards the north, the two models are almost perpendicular. This can be seen in Fig. $7 \mathrm{~b}$ as a smaller peak at $-65^{\circ}$.

\subsubsection{North America}

The understanding of regional tectonics in North America is continuously improved (e.g., Humphreys and Coblentz, 2007). Seismic anisotropy beneath North America has been addressed by numer- 

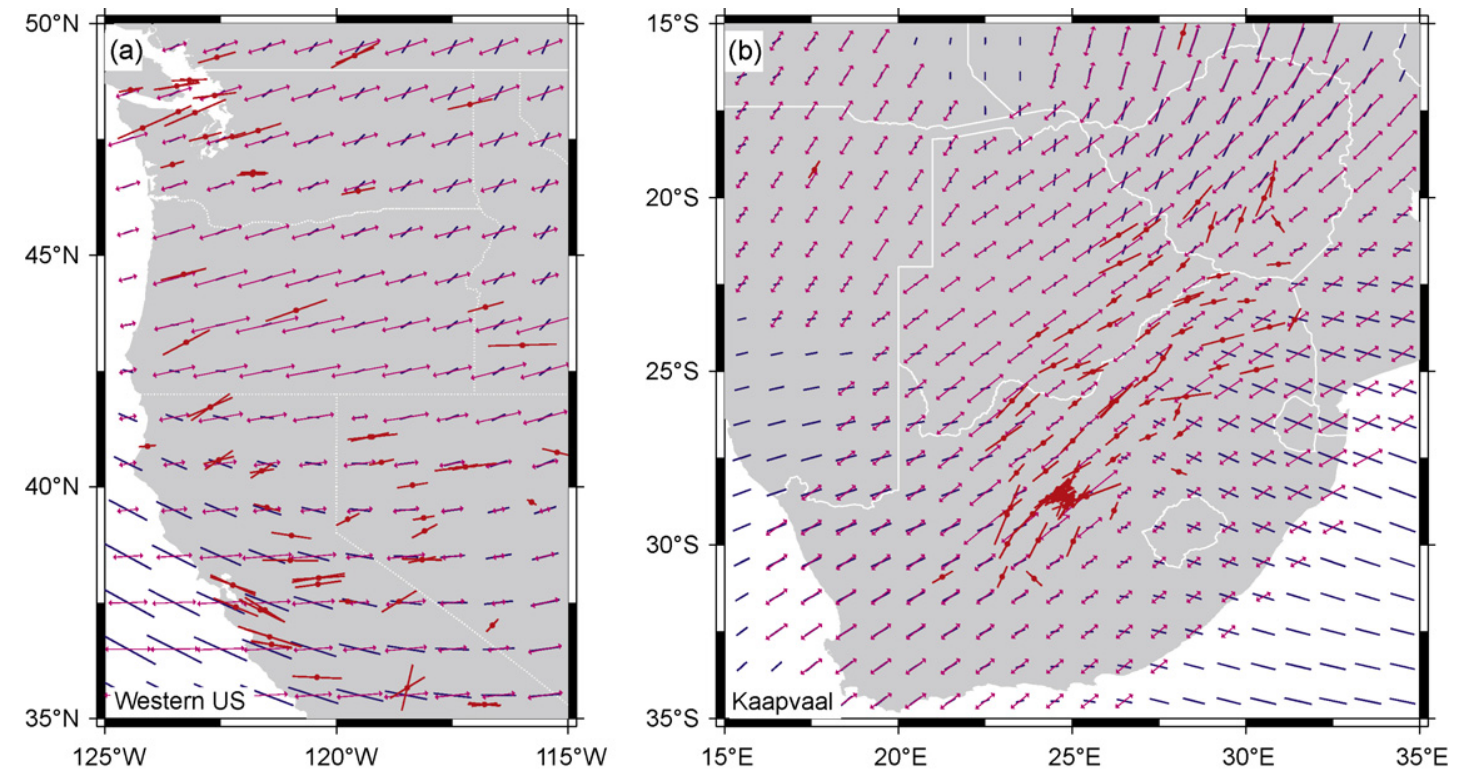

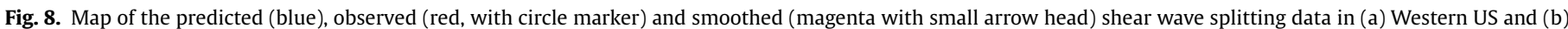

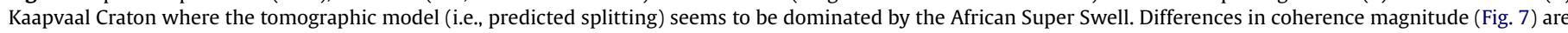

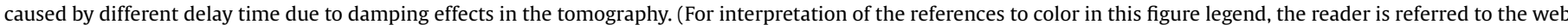
version of the article.)

ous authors (see references in Walker et al., 2004a,b; Fouch and Rondenay, 2006; Bokelmann and Wüstefeld, 2009). The pertaining mantle flow is mainly controlled by the various tectonic settings ranging from cratons in the north (e.g., Bokelmann, 2002a,b), mountain ranges in the east (e.g., Barruol et al., 1997; Fouch et al., 2000), and continental hotspot (e.g., Waite et al., 2005) and subduction in the west that could interfere with strike-slip tectonics to produce a complex toroidal mantle flow pattern (e.g., Xue and Allen, 2007; Zandt and Humphreys, 2008). The splitting dataset presented in this study indicates good correlation with the splitting predicted from surface-wave azimuthal anisotropy in North America (Figs. 7c and 12). Montagner et al. (2000) observed however a rotation of $+30^{\circ}$ between observed and predicted splitting in the Western US (Fig. 8a). In this region, the coherence of the new dataset has improved (Fig. 7d), likely due to the larger amount of splitting data (109 measurements today versus 47 available in 1996), but perhaps also due to the more recent tomographic model used in this study that may provide an improved lateral resolution. The resulting misfit is reduced to a slight rotation of $-10^{\circ}$ for all of North America. In Western North America the angular misfit is precisely $0^{\circ}$. This suggests that surface waves and shear wave splitting experience the same anisotropic structures (Fig. 8a) and therefore, that the apparent complexity of the crustal tectonics in this region may be overlying a mantle structure characterized by a simpler pattern at longer wavelength. It thus appears to be consistent to invert the two datasets together as has been done recently by Marone and Romanowicz (2007).

\subsubsection{Kaapvaal Craton}

Several studies analyzed the Kaapvaal upper mantle anisotropy by using either SKS wave splitting (e.g., Vinnik et al., 1996; Barruol and Ben Ismail, 2001; Silver et al., 2001; Fouch et al., 2004) or the information brought to the surface by kimberlite nodules (e.g., BenIsmail et al., 2001). Silver et al. (2001) and Gao et al. (2002) point out that the fast orientations do not correlate with plate motion directions of Gripp and Gordon (2002). The fast orientation correlates however very well with regional geologic trends, suggesting lithospheric origins of anisotropy. Furthermore, a high-density array in the Kimberley region found small-scale variations in shear wave splitting parameters, which can only be explained by lithospheric origins of anisotropy (Fouch et al., 2004).

In global tomographic models, one of the most intriguing features is the African Superswell (e.g., Nyblade and Robinson, 1994; Ritsema and van Heijst, 2000; Conrad and Gurnis, 2003), which is an ongoing, large-scale, northward oriented mantle upwelling. This upwelling can provide an explanation for the predicted splitting (Figs. 2b and $8 \mathrm{~b}$ ) particularly because of the absence of predicted splitting beneath the Namibia-Botswana border region (Fig. 8b), since vertically oriented anisotropy is not included in the methods used here. The presence of two peaks in the regional coherence function (Fig. 7e) may indicate that the anisotropy observed by tomographic studies is not only related to the ongoing mantle upwelling, but also related to ancient lithospheric anisotropy, at least in the upper mantle regions.

\subsubsection{The East African rift zone}

Rifting along the East African Rift Valley (EAR) has been analyzed at mantle to crustal scales by various studies (see Kendall et al., 2006 for a review). Collectively, the results support a model for magma assisted rifting in Ethiopia with an increase in melt production towards the Red Sea, which is strongly supported by the prediction of partial melt on the basis of $\mathrm{P}$ - and S-wave tomography (Bastow et al., 2005, 2008). In Tanzania and Kenya, fast split shear waves parallel the E and $\mathrm{W}$ arms of the EAR that encircle the Tanzanian craton (Gao et al., 1997; Walker et al., 2004a,b).

The coherence between observed and predicted splitting is rather strong with a maximum at $0^{\circ}$ deviation (Figs. 7f and 13). The strong coherence is mainly due to high correlation of both direction and amplitude of splitting between the predicted and interpolated datasets beneath Afar (Fig. 13). Kendall et al. (2006) proposed a suite of different causes of anisotropy beneath the East African rift system. The main cause of anisotropy is attributed to thin melt pockets directly beneath the rift zone, oriented parallel to the rift axis. Away from the rift axis, the lithospheric LPO is likely related to pre-existing fabric, while beneath the lithosphere the LPO could be due to viscous coupling between the base of the 
lithosphere and large-scale mantle upwelling. This model explains the rift-parallel fast splitting orientations in the rift valley. Such explanation leaves the good correlation somewhat surprising, since global surface waves are not expected to resolve that feature. The splitting delay times predicted in this area are relatively low, which may be due to two perpendicular anisotropic orientations (see discussion for Australia). An alternative explanation might be that the mantle upwelling beneath the rift causes vertically oriented fast axis in the mantle. These do not contribute to the observed and the predicted splitting.

\subsubsection{Central Asia}

In Central Asia (Figs. 7g and 14), more than 250 measurements are now available, in comparison with the 33 available before 1997. The new model seems to be less coherent (Fig. $7 \mathrm{~g}$ ) than the previous one, as discussed in Montagner et al. (2000), and it is characterized by the presence of two peaks in the coherence function at $+15^{\circ}$ and $-70^{\circ}$. Montagner et al. (2000) used a local high-resolution tomographic model (Griot et al., 1998) for calculating the predicted splitting. The two compared datasets seem to be rotated by $20^{\circ}$. The main region of discrepancy is the Tibetan Plateau, while coherence is good for the Tien Shan basin and the North China craton, in the North-West and North-East of Fig. 14, respectively. In general, discrepancies between the global (Montagner and Tanimoto, 1991) and local (Griot et al., 1998) tomographic datasets highlight the importance of local high-resolution tomography that may be sensitive to shorter wavelength structures. This regional analysis also suggests that more data do not necessarily imply a better coherence since local studies involving a large number of stations over a limited space may strongly bias the general coherence function at the regional and global scale. They conclude that future approaches should consider the effect of different data density in greater detail. New azimuthal anisotropy tomographic models of Central Asia with an enhanced lateral resolution are presently issuing. Consequently time is ripe for a new quantitative comparison between SKS splitting data and tomographic models, but it is beyond the scope of this paper.

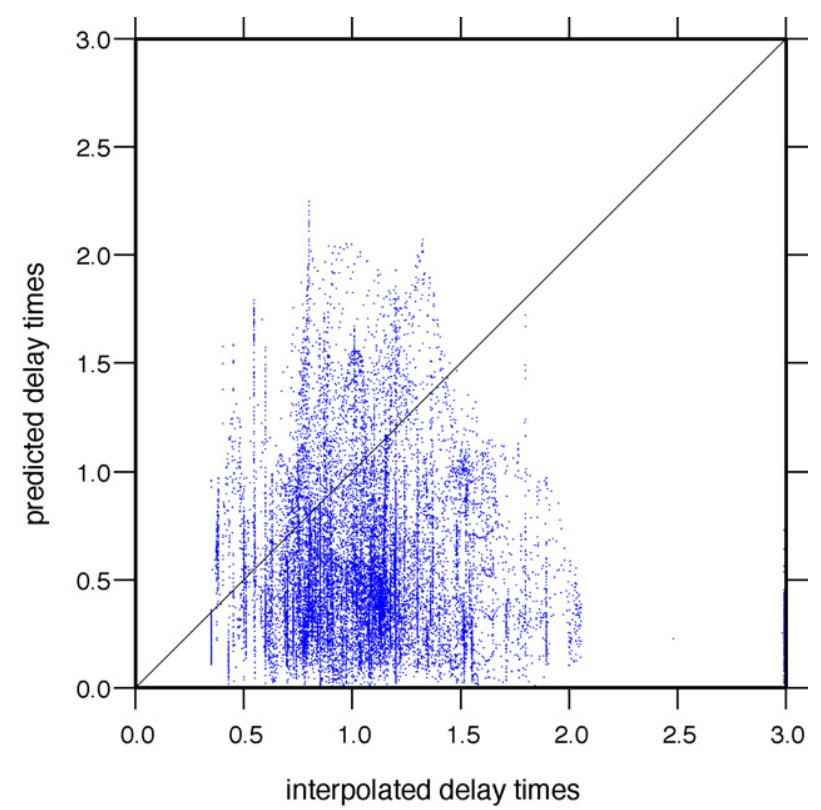

Fig. 9. Scatter-plot of predicted splitting delay versus observed splitting delay. The predicted delay times are generally smaller, indicating a bias from the tomography, probably due to damping effects.

\subsubsection{Australia}

The coherence in Australia is rather good (Figs. 7h and 15). Given the complex anisotropy described by other studies of this area, this is somewhat surprising. Debayle et al. (2005) found that Australia is the only continent where azimuthal anisotropy (inferred from surface waves) correlates well with present day absolute plate motion. This correlation is most significant at depths between 150 and $300 \mathrm{~km}$. In Australia many stations are observed as isotropic, i.e., Nulls from a broad range of backazimuths. Heintz and Kennett $(2005,2006)$ point out that this apparent isotropy at these stations is also consistent with two layers of mutually perpendicular anisotropy orientations (Silver and Savage, 1994; Barruol and Hoffmann, 1999).

The predicted shear wave splitting contains a few regions of negligible splitting amplitude (central Northern Territory, just south of Western Australia, and in Central New South Wales; see Fig. 15). In our approach, the predicted splitting is calculated from 19 layers, each $25 \mathrm{~km}$ thick. The correlation between non-Null observations

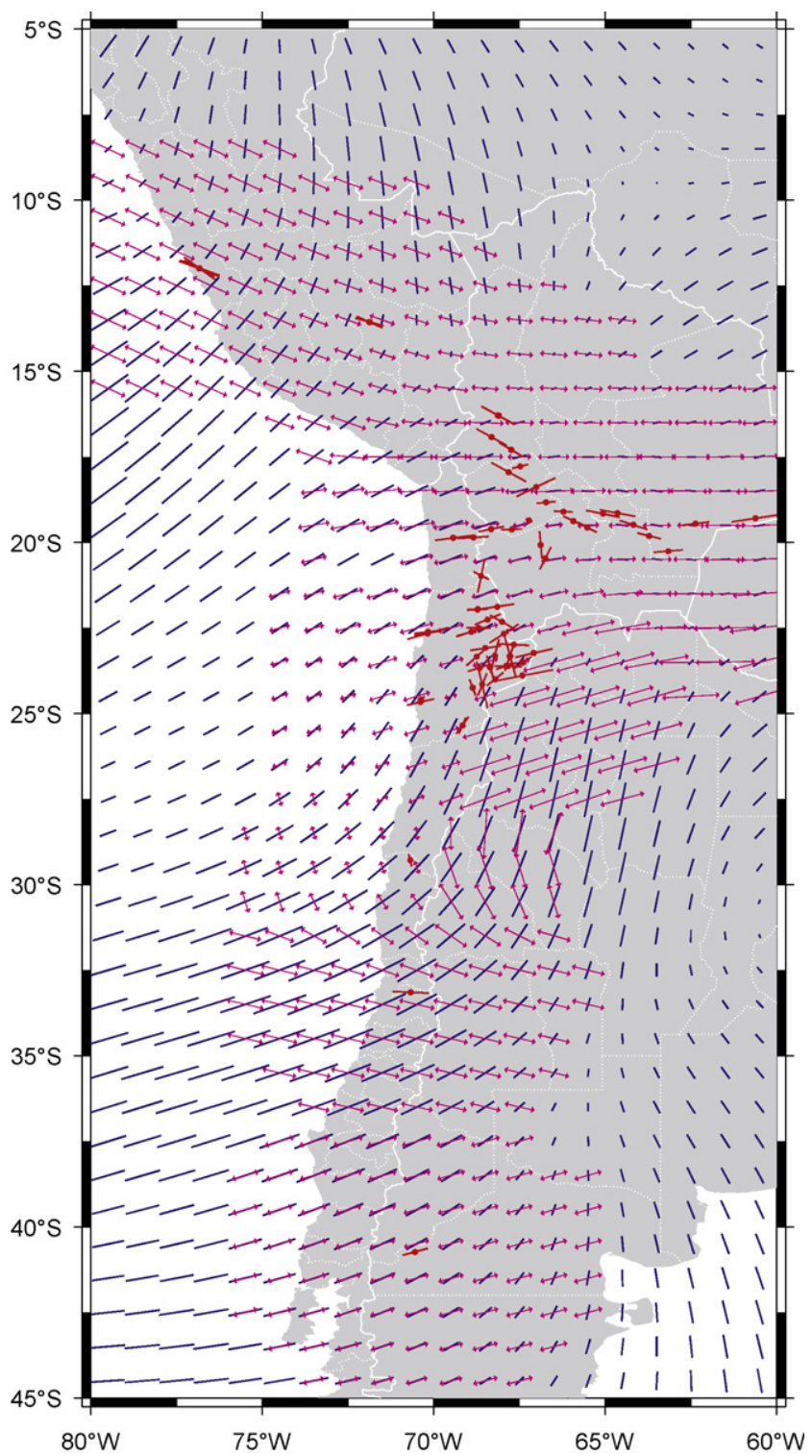

Fig. 10. Map of the predicted (blue), observed (red, with circle marker) and smoothed (magenta with small arrow head) shear wave splitting data in the Andes. (For interpretation of the references to color in this figure legend, the reader is referred to the web version of the article.) 


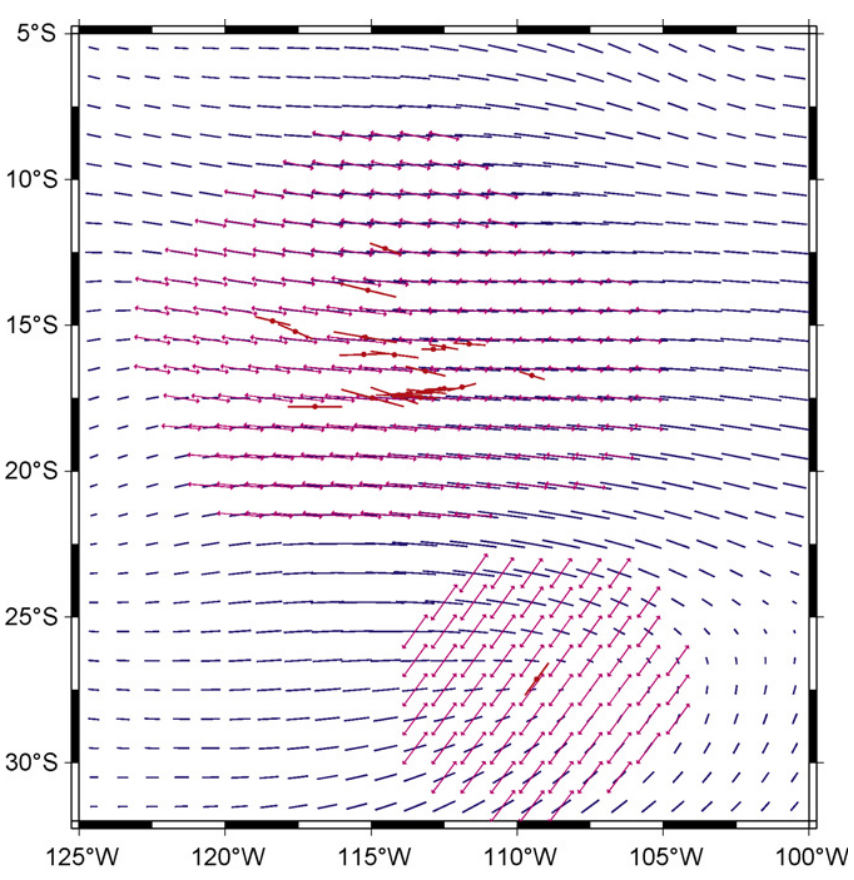

Fig. 11. Map of the predicted (blue), observed (red, with circle marker) and smoothed (magenta with small arrow head) shear wave splitting data in the East Pacific. (For interpretation of the references to color in this figure legend, the reader is referred to the web version of the article.)

and predicted splitting is very good, indicating that such gradual change in anisotropy orientation with depth mimics the non-Null splitting observations well. This in turn indicates that assuming a two layer case may be an oversimplification.

\section{Discussion}

Generally, the resolution of global anisotropic surface-wave models is thought to not be better than a thousand kilometres. For an increasing number of regions, recent high-resolution regional anisotropic tomographic models are available, and future studies should address their correlation with regional splitting data in more detail. For the global model, the dependence of correlation on search radius in Fig. 6b may suggest that resolution capability is somewhat better than the initially thought thousand kilometres. This is true at least for the parts of the Earth that contain the most seismological stations. These areas correspond to the seismically best-resolved portions on Earth, obviously for shear wave splitting but also in surface-wave data due to the higher density of crossing ray paths in those areas. The use of Voronoi cells allows the tomographic model of Debayle et al. (2005) to reflect spatially varying resolutions. The drop-off in correlation below $400 \mathrm{~km}$ is interesting, since we would be able to see that effect only if there is resolution of surface-wave data for those best-resolved parts of the Earth down to $400 \mathrm{~km}$ length scales, which is considerably better than we expected. Whether or not this is the correct explanation for the decay below $400 \mathrm{~km}$, this resolution study is very encouraging, since it indicates lateral surface-wave resolution somewhat below a thousand kilometres for the well-resolved portion of the Earth. The resolution will be considerably weaker in less well-covered regions. A recent study of the Canadian shield (Bokelmann and Wüstefeld, 2009) has suggested that surfacewave anisotropy models do not yet have a similar resolution there, which would be required to distinguish inner-cratonic variations of anisotropy.

This will probably change somewhat in the next years, with the availability of massive regional datasets. Also methodological developments such as simultaneous inversions of splitting and

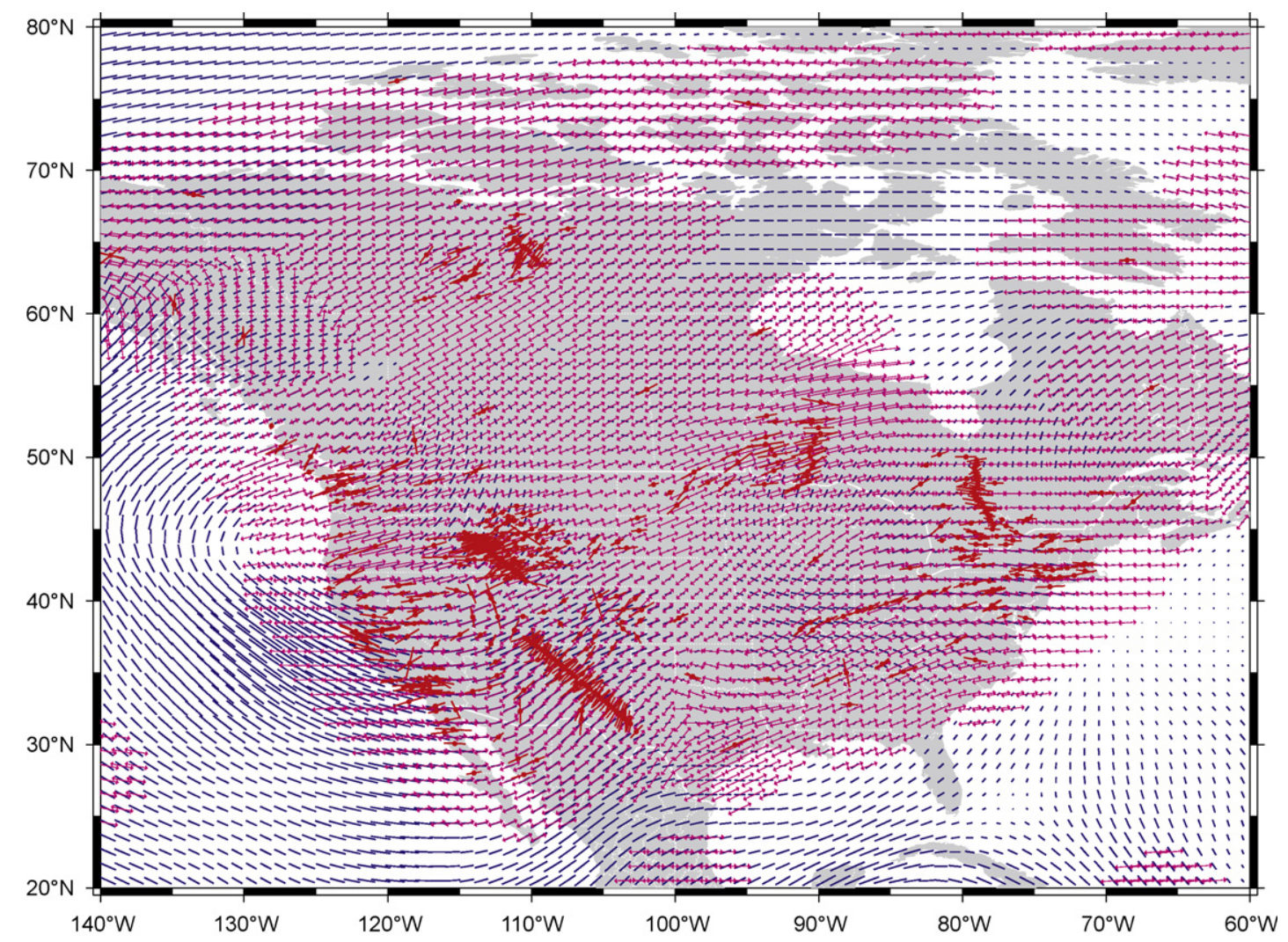

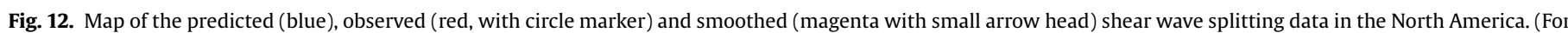
interpretation of the references to color in this figure legend, the reader is referred to the web version of the article.) 


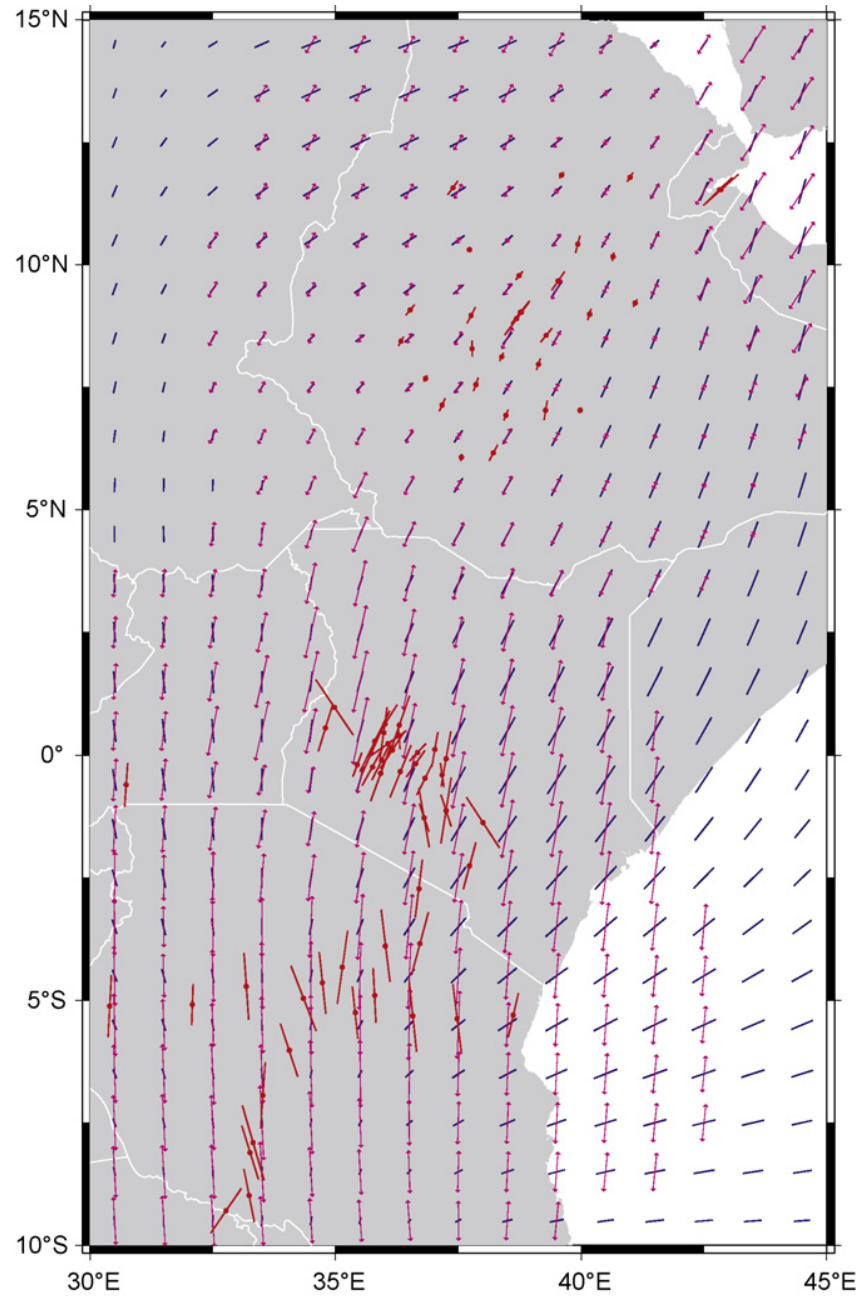

Fig. 13. Map of the predicted (blue), observed (red, with circle marker) and smoothed (magenta with small arrow head) shear wave splitting data in East Africa. (For interpretation of the references to color in this figure legend, the reader is referred to the web version of the article.)

surface-wave data are quite useful (e.g., Marone and Romanowicz, 2007).

A limitation of our method is that no Null stations, i.e., apparently isotropic stations, are included. The explanation of such Null stations is not yet completely understood as ever more evidence suggests that at least the upper part of the mantle is anisotropic. This evidence is based on seismological observations as presented in this paper and also on mineralogical studies (e.g., Ben Ismail and Mainprice, 1998; Mainprice et al., 2000; Holtzman et al., 2003). Nulls stations do not necessarily imply pervasive upper mantle isotropy, but may for example be caused by two anisotropic layers with mutually perpendicular fast orientations (e.g., Silver and Savage, 1994; Heintz and Kennett, 2006). Null stations may also not imply large-scale upper mantle isotropy. For instance, P-polarization analysis at station PPT in Tahiti Island (Fontaine et al., 2009) clearly demonstrates that the isotropy deduced from SKS splitting, located vertically beneath the station, has a restricted lateral extent, implying that such a short-scale upper mantle structure can hardly be visible in surface-wave tomographies.

The database contains only a limited amount of multi-layer cases. For the bulk of data, the observed (apparent) splitting parameters reflect the vertical integration of the different layers of the surface-wave anisotropic model Although the model is divided in 19 layers between 40 and $500 \mathrm{~km}$ depth, the radial correlation length limits the actual number of independent layers to 4 or 5 . These layers can in turn display effectively the same azimuth and so the real number of layers with different orientations (in complex areas) may be at the most two or three. However, it is important to note that in many areas these azimuthal variations and this stratification of anisotropy are real and significant, although they cannot directly be inferred from shear wave splitting (Silver and Savage, 1994; Rümpker and Silver, 1998; Saltzer et al., 2000).

The predicted delay times are smaller than the observed. Fig. 9 shows a scatter-plot, comparing the predicted delay times of the surface-wave model with those delay times of the smoothed, observed delay times for smoothing parameters of $R=600 \mathrm{~km}$. The majority of the data are located on the right-hand side of the graph, implying that surface-wave-predicted delay times are biased to smaller values. This also shows up in relatively low coherence (Fig. 4). Our findings of best coherence between the two datasets at approximately $600 \mathrm{~km}$ is in agreement with the stochastic model of anisotropy correlation by Becker et al. (2007), which reveals a relatively short correlation length of splitting parameters of $L \sim 550 \mathrm{~km}$ for orogens and volcanic zones.

There is only a limited amount of shear-wave splitting measurements in the oceans although future deployments of Ocean Bottom Seismometers will eventually enhance the global splitting coverage (e.g., Suetsugu et al., 2005). This should allow for a separate analysis of continents having mostly thick and old lithosphere, with sometimes ancient anisotropy orientations, and oceans having a much more recent and simpler history (Montagner, 2002; Becker et al., 2003), which will probably include exciting new possibilities such

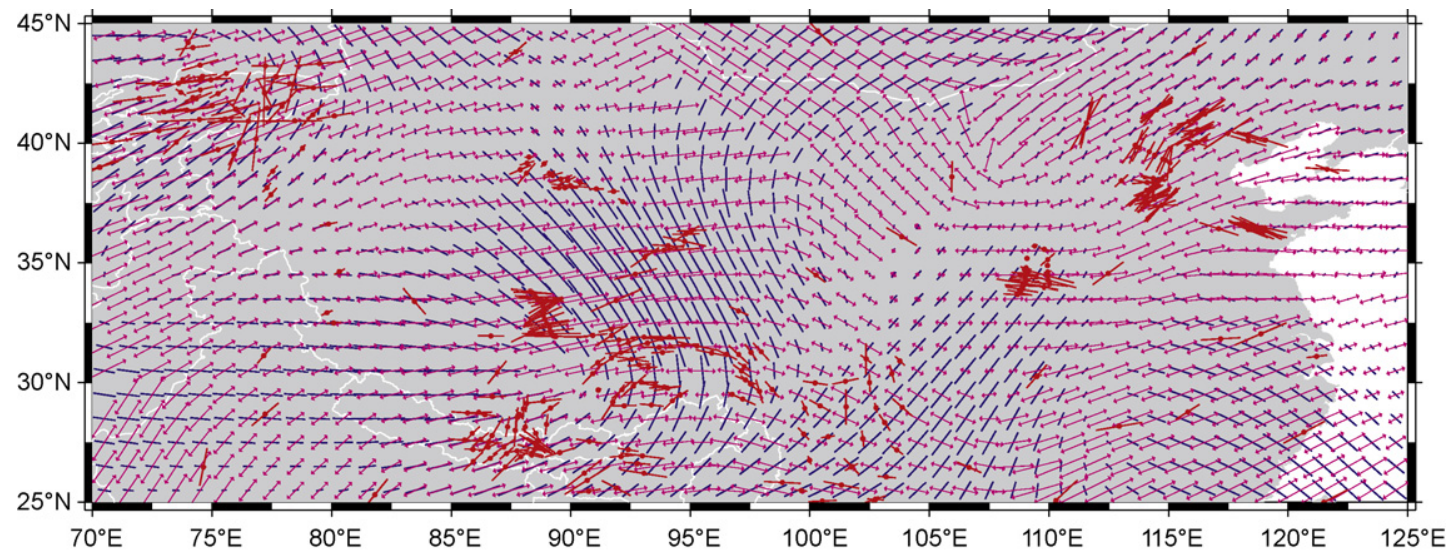

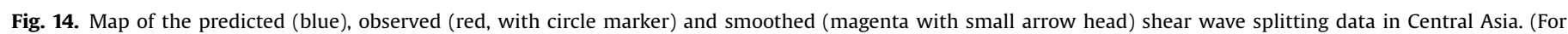
interpretation of the references to color in this figure legend, the reader is referred to the web version of the article.) 


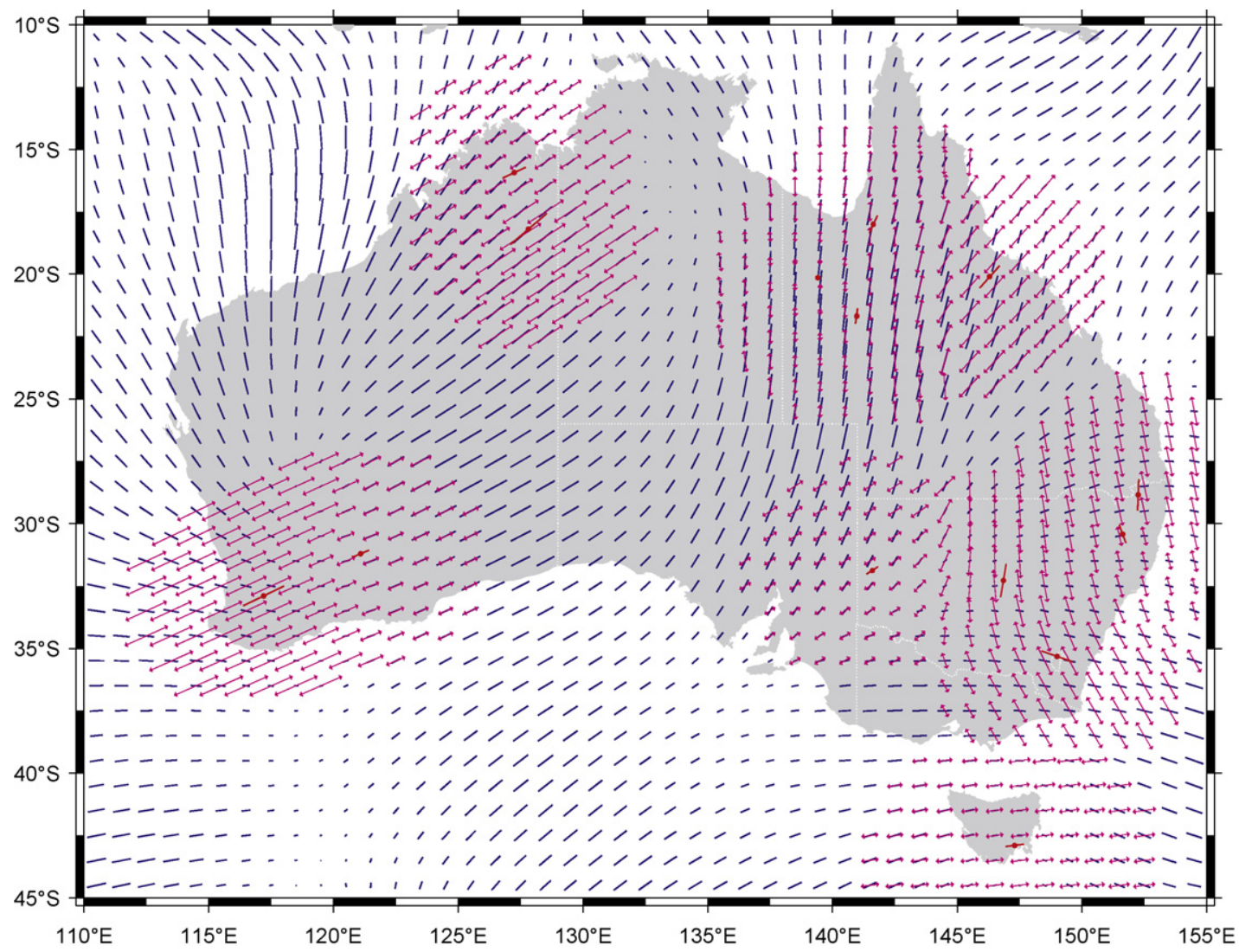

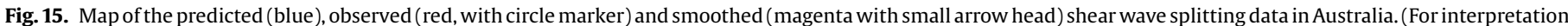
of the references to color in this figure legend, the reader is referred to the web version of the article.)

as observing hotspot-induced mantle flow, small-scale convection, plume-ridge interaction, etc.

The coverage of shear-wave splitting data that are available at this point does not allow accepting or rejecting predominantly East-West mantle flow (e.g., Doglioni, 1994) at global scale as manifested in fast directions. The maximum observed in Fig. 3b is clearly an artefact of the spatial sampling and probably includes many observations of fossil lithospheric anisotropy.

\section{Conclusion}

In this paper, we have compared shear-wave splitting measurements made around the world with predicted splitting parameters derived from anisotropic surface-wave tomography. This allowed us to show that the two measures of anisotropy are indeed correlated, even though they have very different lateral and vertical resolution. This correlation is apparently supported by the fact that both measures are mostly sensitive to the upper mantle (e.g., Sieminski et al., 2007). The quality of the measurements and resulting models allows us to address the limit of lateral resolution of the anisotropic surface-wave model. Finally, the agreement of the two different methods highlights the fact that the two techniques are fully complementary since they are sensitive to vertical or lateral variations of upper mantle flow and therefore deserve to be twined together in studies aiming at mapping upper mantle deformation.

\section{Acknowledgements}

We would like to thank Derek Schutt and Matt Fouch for their initial work of collecting the splitting parameters and for providing them online. Alexis Rochat helped us entering additional SKS pub- lished data. Special thank goes to all colleagues who already entered their results to the database. We are grateful to Birgit Müller and Oliver Heidbach of the University of Karlsruhe for providing the smoothing code. We thank Ian Bastow for discussion on the East African Rift. The reviews by of Matt Fouch and Christine Houser greatly improved our manuscript.

\section{References}

Ando, M., Ishikawa, Y., Wada, H., 1980. S-wave anisotropy in the upper mantle under a volcanic area in Japan. Nature 286, 43-46.

Assumpcao, M., Heintz, M., Vauchez, A., Silva, M.E., 2006. Upper mantle anisotropy in SE and Central Brazil from SKS splitting: evidence of asthenospheric flow around a cratonic keel. Earth Planet. Sci. Lett. 250 (1-2), 224-240.

Babuska, V., Plomerova, J., Sileny, J., 1984. Spatial variations of P-residuals and deep-structure of the European lithosphere. Geophys. J. R. Astron. Soc. 79 (1) 363-383.

Backus, G.E., 1962. Long-wave elastic anisotropy produced by horizontal layering. J Geophys. Res. 67 (11), 4427-4440.

Barruol, G., Ben Ismail, W., 2001. Upper mantle anisotropy beneath the African IRIS and Geoscope stations. Geophys. J. Int. 146 (2), 549-561, doi:10.1046/j.0956540x.2001.01481.x.

Barruol, G., Granet, M., 2002. A Tertiary asthenospheric flow beneath the southern French Massif Central indicated by upper mantle seismic anisotropy and related to the west Mediterranean extension. Earth Planet. Sci. Lett. 202, 31-47, doi:10.1016/S0012-821X(02)00752-5.

Barruol, G., Hoffmann, R., 1999. Upper mantle anisotropy beneath the Geoscope stations. J. Geophys. Res. 104 (B5), 10757-10773.

Barruol, G., Souriau, A., Vauchez, A., Diaz, J., Gallart, J., Tubia, J., Cuevas, J., 1998. Lithospheric anisotropy beneath the Pyrenees from shear wave splitting. J. Geophys. Res. 103 (B12), 30039-30053.

Barruol, G., Silver, P.G., Vauchez, A., 1997. Seismic anisotropy in the eastern US: deep structure of a complex continental plate. J. Geophys. Res. 102, 8329-8348.

Bastow, I.D., Stuart, G.W., Kendall, J.M., Ebinger, C.J., 2005. Upper-mantle seismic structure in a region of incipient continental breakup: northern Ethiopian rift Geophys. J. Int. 162, 479-493, doi:10.1111/j.1365-246X.2005.02666.x.

Bastow, I.D., Nyblade, A.A., Stuart, G.W., Rooney, T., Benoit, M.H., 2008. Upper mantle seismic structure beneath the Ethiopian hotspot: rifting at the edge of the 
African low velocity anomaly. Geochem. Geophys. Geosyst. 9 (12), Q12022, doi:10.1029/2008GC002107.

Becker, T.W., Kellogg, J.B., Ekstrom, G., O'Connell, R.J., 2003. Comparison of azimuthal seismic anisotropy from surface waves and finite strain from global mantlecirculation models. Geophys. J. Int. 155 (2), 696-714.

Becker, T.W., Browaeys, J.T., Jordan, T.H., 2007. Stochastic analysis of shear-wave splitting length scales. Earth Planet. Sci. Lett. 259, 526-540.

Becker, T.W., Chevrot, S., Schulte-Pelkum, V., Blackman, D.K., 2006. Statistical properties of seismic anisotropy predicted by upper mantle geodynamic models. J. Geophys. Res. 111 (B10), B08309.

Behn, M.D., Conrad, C.P., Silver, P., 2004. Detection of upper mantle flow associated with the African Superplume. Earth Planet. Sci. Lett. 224, 259-274.

Ben-Ismail, W., Barruol, G., Mainprice, D., 2001. The Kaapvaal craton seismic anisotropy: petrophysical analyses of upper mantle kimberlite nodules. Geophys. Res. Lett. 28, 2497-2500.

Ben Ismail, W., Mainprice, D., 1998. An olivine fabric database: an overview of upper mantle fabrics and seismic anisotropy. Tectonophysics 296 (1-2), 145157.

Bird, P., Li, Y., 1996. Interpolation of principal stress directions by nonparametric statistics: global maps with confidence limits. J. Geophys. Res. 101 5435-5444.

Bokelmann, G.H.R., 1995. P-wave array polarization analysis and effective anisotropy of the brittle crust. Geophys. J. Int. 120 (1), 145-162.

Bokelmann, G.H.R., 2002a. Convection-driven motion of the North American craton: evidence from P-wave anisotropy. Geophys. J. Int. 248 (2), 278-287.

Bokelmann, G.H.R., 2002b. Which forces drive North America? Geology 30 (11), $1027-1030$

Bokelmann, G.H.R., Wüstefeld, A., 2009. Comparing crustal and mantle fabric from the North American craton using magnetics and seismic anisotropy. Earth Planet. Sci. Lett. 277 (3-4), 355-364, doi:10.1016/j.epsl.2008.10.032.

Conrad, C.P., Behn, M.D., Silver, P.G., 2007. Global mantle flow and the development of seismic anisotropy: differences between the oceanic and continental upper mantle. J. Geophys. Res. 112, B07317.

Conrad, C.P., Gurnis, M., 2003. Seismic tomography, surface uplift, and the breakup of Gondwanaland: integrating mantle convection backwards in time. Geochem. Geophys. Geosyst. 4 (3), 1031

Crampin, S., 1984. Effective anisotropic elastic constants for wave propagation through cracked solids. Geophys. J. R. Astron. Soc. 76, 135-145.

Debayle, E., Kennett, B., Priestley, K., 2005. Global azimuthal seismic anisotropy and the unique plate motion deformation of Australia. Nature 433, 509-512.

Doglioni, C., 1994. Foredeeps versus subduction zones. Geology 22 (3), 271-274.

Doglioni, C., Carminati, E., Bonatti, E., 2003. Rift asymmetry and continental uplift. Tectonics $22(8), 1024$.

Evans, M.S., Kendall, J., Willemann, R.J., 2006. Automated SKS splitting and uppermantle anisotropy beneath Canadian seismic stations. Geophys. J. Int. 165 (3), 931-942.

Flesch, L.M., Holt, W.E., Silver, P.G., Stephenson, M., Wang, C., Chan, W.W., 2005. Constraining the extent of crust-mantle coupling in central Asia using GPS, geologic, and shear wave splitting data. Earth Planet. Sci. Lett. 238, 248-268.

Fontaine, F.R., Barruol, G., Kennett, B.L.N., Bokelmann, G.H.R., Reymond, D., 2009 Upper mantle anisotropy beneath Australia and Tahiti from P wave polarization: Implications for real-time earthquake location. J. Geophys. Res. 114 (B03306), doi:10.1029/2008JB005709.

Fontaine, F.R., Barruol, G., Tommasi, A., Bokelmann, G.H.R., 2007. Upper-mantle flow beneath French Polynesia from shear wave splitting. Geophys. J. Int. 170, 1262-1288, doi:10.1111/j.1365-246X.2007.03475.x.

Fontaine, F.R., Hooft, E.E.E., Burkett, P.G., Toomey, D.R., Solomon, S.C., Silver, P.G., 2005 Shear-wave splitting beneath the Galápagos archipelago. Geophys. Res. Lett. 32, L21308, doi:10.1111/j.1365-246X.2007.03475.x.

Forsyth, D.W., 1975. A new method for the analysis of multi-mode surface-wave dispersion: application to Love-wave propagation in the east Pacific. Bull. Seis. Soc. Am. 65 (2), 323-342.

Fouch, M.J., Fischer, K.M., Parmentier, E.M., Wysession, M.E., Clarke, T.J., 2000. Shear wave splitting, continental keels, and patterns of mantle flow. J. Geophys. Res. 105 (B3), 6255-6275.

Fouch, M.J., Rondenay, S., 2006. Seismic anisotropy beneath stable continental interiors. Phys. Earth Planet. Int. 158 (2-4), 292-320.

Fouch, M.J., Silver, P.G., Bell, D.R., Lee, J.N., 2004. Small-scale variations in seismic anisotropy near Kimberley, South Africa. Geophys. J. Int. 157, 764-774.

Gao, S., Davis, P.M., Liu, H., Slack, P.D., Rigor, A.W., Zorin, Y.A., Mordvinova, V.V., Kozhevnikov, V.M., Logatchev, N.A., 1997. SKS splitting beneath continental rift zones. J. Geophys. Res. 102 (B10), 2281-22798.

Gao, S.S., Silver, P.G., Liu, K.H., 2002. Mantle discontinuities beneath Southern Africa. Geophys. Res. Lett. 29 (10), 1491, doi:10.1029/2001GL013834.

Griot, D., Montagner, J., Tapponnier, P., 1998. Phase velocity structure from Rayleigh and Love waves in Tibet and its neighbouring regions. J. Geophys. Res. 103, $21215-21232$.

Gripp, A.E., Gordon, R.G., 2002. Young tracks of hotspots and current plate velocities. Geophys. J. Int. 150 (2), 321-361, doi:10.1046/j.1365-246X.2002.01627.x.

Harmon, N., Forsyth, D.W., Fischer, K.M., Webb, S.C., 2004. Variations in shearwave splitting in young Pacific seafloor. Geophys. Res. Lett. 31, L15609, doi:10.1029/2004GL020495.

Helffrich, G., Wiens, D.A., Vera, E., Barrientos, S., Shore, P., Robertson, S., Adaros, R., 2002. A teleseismic shear-wave splitting study to investigate mantle flow around South America and implications for plate-driving forces. Geophys. J. Int. 149 (1), F1-F7, doi:10.1046/j.1365-246X.2002.01636.x.
Heintz, M., Kennett, B.L.N., 2005. Continental scale shear wave splitting analysis: Investigation of seismic anisotropy underneath the Australian continent. Earth Planet. Sci. Lett. 236 (1-2), 106-119.

Heintz, M., Kennett, B.L.N., 2006. The apparently isotropic Australian upper mantle. Geophys. Res. Lett. 33, L15319, doi:10.1029/2006GL026401.

Hess, H.H., 1964. Seismic anisotropy of the uppermost mantle under oceans. Nature 203, 629-631.

Holtzman, B.K., Kohlstedt, D.L., Zimmerman, M.E., Heidelbach, F., Hiraga, T., Hustoft, J., 2003. Melt segregation and strain partitioning: implications for seismic anisotropy and mantle flow. Science 29 (301), 1227-1230, doi:10.1126/science. 1087132.

Humphreys, E.D., Coblentz, D.D., 2007. North American dynamics and western U.S. tectonics. Rev. Geophys. 45, RG3001, doi:10.1029/2005RG000181.

Kendall, J.M., Pilidou, S., Keir, D., Bastow, I., Stuart, G., Ayele, A., 2006. Mantle upwellings, melt migration and magma assisted rifting in Africa: insights from seismic anisotropy. In: Yirgu, G., Ebinger, C.J., Maguire, P.K.H. (Eds.), Structure and Evolution of the Rift Systems within the Afar Volcanic Province, Northeast Africa. Geol. Soc. London - Spec. Pub., 259, pp. 57-74.

Kendall, J.M., Stuart, G., Ebinger, C., Bastow, I., Keir, D., 2005. Magma-assisted rifting in Ethiopia. Nature 433, 146-148.

Kendall, J.M., 1994. Teleseismic arrivals at a mid-ocean ridge: effect of mantle melt and anisotropy. Geophys. Res. Lett. 21, 301-304.

Kneller, E.A., van Keken, P.E., Katayama, I., Karato, S., 2007. Stress, strain, and B-type olivine fabric in the fore-arc mantle: sensitivity tests using highresolution steady-state subduction zone models. J. Geophys. Res. 112 (B4), B04406, doi:10.1029/2006JBO.

Larmat, C., Montagner, J.-P., Fink, M., Capdeville, Y., Tourin, A., Clévédé, E., 2006. Time-reversal imaging of seismic sources and application to the great Sumatra earthquake. Geophys. Res. Lett. 33, L19312, doi:10.1029/2006GL026336.

Levin, V., Droznin, D., Park, J., Gordeev, E., 2004. Detailed mapping of seismic anisotropy with local shear waves in southeastern Kamchatka. Geophys. J. Int. 158 (3), 1009-1023.

Lucente, F.P., Margheriti, L., Piromallo, C., Barruol, G., 2006. Seismic anisotropy reveals the long route of the slab through the western-central Mediterranean mantle. Earth Planet. Sci. Lett. 241, 517-529, doi:10.1016/j.epsl.2005.10.041.

Maggi, A., Debayle, E., Priestley, K., Barruol, G., 2006. Azimuthal anisotropy of the Pacific region. Earth Planet. Sci. Lett. 250, 53-71, doi:10.1016/j.epsl.2006. 07.010.

Mainprice, D., Barruol, G., Ben Ismail, W., 2000. The seismic anisotropy of the Earths mantle: from single crystal to polycrystal. In: Karato, S.I., Forte, A., Liebermann, R.C., Masters, G., Stixrude, L. (Eds.), Earths Deep Interior: Mineral Physics and Tomography from the Atomic to the Global Scale. Geophysical Monograph., vol. 117. AGU, Washington, DC, pp. 237-264.

Mainprice, D., Silver, P.G., 1993. Interpretation of SKS-waves using samples from the subcontinental lithosphere. Phys. Earth Planet. Int. 78, 257-280.

Margheriti, L., Lucente, F.P., Pondrelli, S., 2003. SKS splitting measurements in the Apenninic-Tyrrhenian domain (Italy) and their relation with lithospheric subduction and mantle convection. J. Geophys. Res. 108, B2218, doi:10.1029/ 2002JB001793.

Marone, F., Romanowicz, B., 2007. The depth distribution of azimuthal anisotropy in the continental upper mantle. Nature 447 (7141), 198-201.

Montagner, J.-P., Marty, B., Stutzmann, E., Sicilia, D., Cara, M., Pik, R., Lévêque, J.J., Roult, G., Beucler, E., Debayle, E., 2007. Mantle upwellings and convective instabilities revealed by seismic tomography and helium isotope geochemistry beneath eastern Africa. Geophys. Res. Lett. 34, L21303, doi:10.1029/ 2007GL031098.

Montagner, J.-P., 1994. Can seismology tell us anything about convection in the mantle? Rev. Geophys. 32 (2), 115-137.

Montagner, J.-P., 2002. Upper mantle low anisotropy channels below the Pacific Plate. Earth Planet. Sci. Lett. 202, 263-274.

Montagner, J.-P., 1986. Dimensional structure of the Indian Ocean inferred from long period surface waves. Geophys. Res. Lett. 13, 315-318.

Montagner, J.-P., Griot-Pommera, D., Lavé, J., 2000. How to relate body wave and surface wave anisotropy? J. Geophys. Res. 105, 19015-19028.

Montagner, J.-P., Tanimoto, T., 1991. Global upper mantle tomography of seismic velocities and anisotropies. J. Geophys. Res. 96 (B12), 20, 337-20, 351.

Müller, B., Wehrle, V., Hettel, S., Sperner, B., Fuchs, K., 2003. A new method for smoothing oriented data and its application to stress data. In: Ameen, M. (Ed.), Fracture and In-situ Stress Characterisation of Hydrocarbon Reservoirs. Geol. Soc. Lond. Spec. Publ., pp. 107-126.

Nakajima, J., Hasegawa, A., 2004. Shear-wave polarization anisotropy and subduction-induced flow in the mantle wedge of northeastern Japan. Earth Planet. Sci. Lett. 225, 365-377.

Nicolas, A., Christensen, N.I., 1987. Formation of anisotropy in upper mantle peridotites-a review. In: Fuchs, K., Froideveaux, C. (Eds.), Composition Structure and Dynamics of the Lithosphere Asthenosphere System. AGU, Washington, DC, pp. 111-123.

Nishimura, C.E., Forsyth, D.W., 1988. Rayleigh wave phase velocities in the Pacific with implications for azimuthal anisotropy and lateral heterogeneities. Geophys. J. Int. 94, 479-501.

Nyblade, A.A., Robinson, S.W., 1994. The African superswell. Geophys. Res. Lett. 21, 765-768.

Polet, J., Silver, P.G., Beck, S., Wallace, T., Zandt, G., Ruppert, S., Kind, R., Rudloff, A., 2000. Shear wave anisotropy beneath the Andes from the BANJO, SEDA, and PISCO experiments. J. Geophys. Res. 105 (B3), 6287-6304. 
Ritsema, J., van Heijst, H., 2000. New seismic model of the upper mantle beneath Africa. Geology 28 (1), 63-66.

Rümpker, G., Silver, P.G., 1998. Apparent shear-wave splitting parameters in the presence of vertically varying anisotropy. Geophys. J. Int. 135 (3), 790-800.

Russo, R.M., Silver, P.G., 1994. Trench-parallel flow beneath the Nazca plate from seismic anisotropy. Science 263, 1105-1111.

Saltzer, R.L., Gaherty, J.B., Jordan, T.H., 2000. How are vertical shear wave splitting measurements affected by variations in the orientation of azimuthal anisotropy with depth? Geophys. J. Int. 141, 374-390.

Savage, M.K., 1999. Seismic anisotropy and mantle deformation: what have we learned from shear wave splitting. Rev. Geophys. 37, 69-106.

Schulte-Pelkum, V., Blackman, D.K., 2003. A synthesis of seismic P and S anisotropy. Geophys. J. Int. 154, 166-178.

Schulte-Pelkum, V., Masters, G., Shearer, P.M., 2001. Upper mantle anisotropy from long-period P polarization. J. Geophys. Res. 106, 21917-21934.

Sebai, A., Stutzmann, E., Montagner, J.-P., Sicilia, D., Beucler, E., 2006. Anisotropic structure of the African upper mantle from Rayleigh and Love wave tomography. Phys. Earth Planet. Int. 155 (1-2), 48-62.

Sieminski, A., Liu, Q., Trampert, J., Tromp, J., 2007. Finite-frequency sensitivity of body waves to anisotropy based upon adjoint methods. Geophys. J. Int. 171 (1), 368-389, doi:10.1111/j.1365-246X.2007.03528.x.

Silver, P.G., 1996. Seismic anisotropy beneath the continents: probing the depths of geology. Annu. Rev. Earth Planet. Sci. 24, 385-432.

Silver, P.G., Chan, W.W., 1991. Shear wave splitting and subcontinental mantle deformation. J. Geophys. Res. 96 (B10), 16429-16454.

Silver, P.G., Savage, M., 1994. The interpretation of shear-wave splitting parameters in the presence of two anisotropic layers. Geophys. J. Int. 119, 949-963.

Silver, P.G., Gao, S.S., Liu, K.H., 2001. Mantle deformation beneath southern Africa. Geophys. Res. Lett. 28 (13), 2493-2496.

Simons, F.J., van der Hilst, R.D., 2003. Seismic and mechanical anisotropy and the past and present deformation of the Australian lithosphere. Earth Planet. Sci. Lett. 211 (3-4), 271-286, doi:10.1016/S0012-821X(03)00198-5.

Smith, D.B., Ritzwoller, M.H., Shapiro, N.M., 2004. Stratification of anisotropy in the Pacific upper mantle. J. Geophys. Res. 109 (B18), B11309.

Steinberger, B., O'Connel, R.J., 1998. Advection of plumes in mantle flow: implications for hotspot motion, mantle viscosity and plume distribution. Geophys. J. Int. 132 (2), 412-434.

Suetsugu, D., Isse, T., Tanaka, S., Obayashi, M., Shiobara, H., Sugioka, H., Kanazawa, T., Fukao, Y., Barruol, G., Reymond, D., 2005. Probing South Pacific mantle plumes with Broadband OBS. Eos 86 (44), 429-435.

Trampert, J., Woodhouse, J.H., 2003. Global anisotropic phase velocity maps for fundamental mode surface waves between 40 and 150 s. Geophys. J. Int. 154, $154-165$.

Vauchez, A., Nicolas, A., 1991. Mountain building: strike parallel motion and mantle anisotropy. Tectonophysics $185,183-201$.
Vinnik, L.P., Farra, V., Romanniwicz, B., 1989. Azimuthal anisotropy in the earth from observations of SKS at GEOSCOPE and NARS broadband stations. Bull. Seis. Soc. Am. 79 (5), 1542-1558.

Vinnik, L.P., Green, R.W.E., Nicolaysen, L.O., 1996. Seismic constraints on dynamics of the mantle of the Kaapvaal craton. Phys. Earth Planet. Int. 95, 139151.

Vinnik, L.P., Kosarev, G.L., Makeyeva, L.I., 1984. Anisotropiya litosfery po nablyudeniyam voln SKS and SKKS. Dokl. Akad. Nauk USSR 278, 1335-1339.

Waite, G.P., Schutt, D.L., Smith, R.B., 2005. Models of lithosphere and asthenosphere anisotropic structure of the Yellowstone hot spot from shear wave splitting. J. Geophys. Res. 110, B11304, doi:10.1029/2004JB003501.

Walker, K.T., Bokelmann, G.H.R., Klemperer, S.L., 2001. Shear-wave splitting to test mantle deformation models around Hawaii. Geophys. Res. Lett. 28, 4319-4322.

Walker, K.T., Bokelmann, G.H.R., Klemperer, S.L., 2004a. Shear-wave splitting beneath the Snake River Plain suggests a mantle upwelling beneath eastern Nevada, USA. Earth Planet. Sci. Lett. 222, 529-542.

Walker, K.T., Bokelmann, G.H.R., Klemperer, S.L., Bock, G., 2005. Shear-wave splitting around the Eifel hotspot: evidence for a mantle upwelling. Geophys. J. Int. 163 (3), 962-980.

Walker, K.T., Nyblade, A.A., Klemperer, S.L., Bokelmann, G.H.R., Owens, T.J., 2004b. On the relationship between extension and anisotropy: constraints from shear wave splitting across the East African Plateau. J. Geophys. Res. 109 (B18), B08302.

Watson, G.S., 1985. Interpolation and smoothing of directed and undirected line data. In: Krishnajah, P.R. (Ed.), Multivariate Analysis-VI. Elsevier Science, New York, pp. 613-625.

Wehrle, V., 1998, Analytische Untersuchung intralithosphärischer Deformationen und Numerische Methoden zur Bestimmung krustaler Spannungsdomänen, PhD thesis (in German), Univ. Karlsruhe, http://digbib.ubka.unikarlsruhe.de/volltexte/12098.

Wolfe, C.J., Silver, P.G., 1998. Seismic anisotropy of oceanic upper mantle: shear wave splitting methodologies and observations. J. Geophys. Res. 103 (B1), 749 771.

Wolfe, C.J., Solomon, S.C., 1998. Plume distribution shear-wave splitting and implications for mantle flow beneath the MELT region of the East Pacific Rise. Science 280, 1230-1232, doi:10.1126/science.280.5367.1230.

Wüstefeld, A., Bokelmann, G.H.R., 2007. Null detection in shear-wave splitting measurements. Bull. Seism. Soc. Am. 97 (4), 1204-1211, doi:10.1785/0120060190.

Wüstefeld, A., Bokelmann, G.H.R., Barruol, G. Lithospheric anisotropy and deformation beneath the East European Craton, Tectonophysics, doi:1010.1016/j.tecto.2009.01.010, in press.

Xue, M., Allen, R.M., 2007. The Fate of the Juan de Fuca Plate: implications for a Yellowstone Plume Head. Earth Planet. Sci. Lett. 264, 266-276, doi:10.1016/ j.epsl.2007.09.047.

Zandt, G., Humphreys, E., 2008. Toroidal mantle flow through the western U.S. slab window. Geology 36 (4), 295-298, doi:10.1130/G24611A.1. 